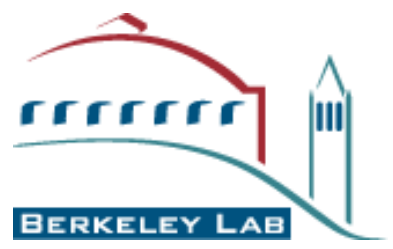

\title{
Modeling Coupled Processes in Clay Formations for Radioactive Waste Disposal
} Hui-Hai Liu, Jonny Rutqvist, Liange Zheng, Eric Sonnenthal,
Jim Houseworth and Jens Birkholzer

Lawrence Berkeley National Laboratory (LBNL) 


\section{Table of Contents}

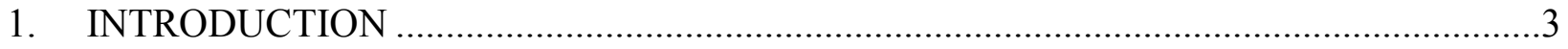

2. Constitutive Relationships for Elastic Deformation of Indurated Clay Rock..........................4

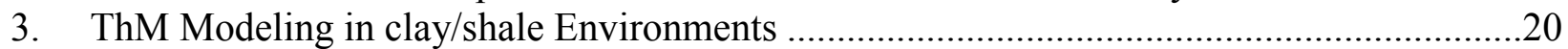

3.1 Modeling Tools for Coupled THM processes ..................................................... 20

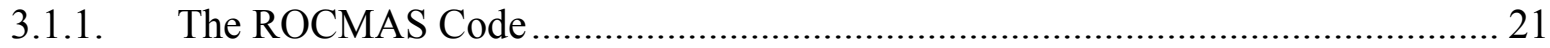

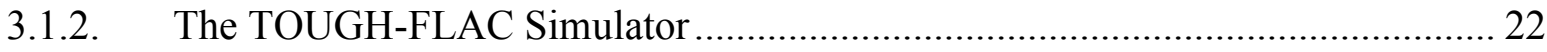

3.1.3. Comparison of ROCMAS and TOUGH-FLAC to Other THM codes .................. 24

3.2 Simulation of a Generic Repository in Clay Host Rock ……...................................... 25

3.1.4. The Repository Design and Heat Load ............................................................ 26

3.1.5. Modeling Sequence, Boundary and Initial Conditions ......................................... 28

3.1.6. Basic THM simulation results ………………................................................ 30

3.1.7. Summary of THM Research for Clay/Shale Environments and Next Step.......... 31

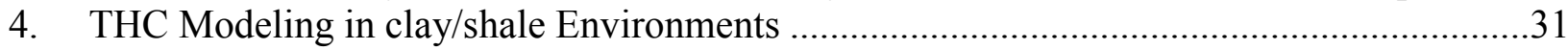

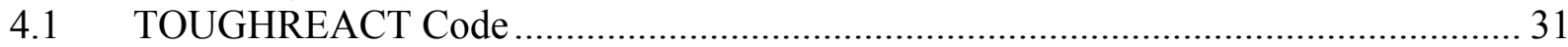

4.1.1. Major Processes Treated by TOUGHREACT .................................................... 32

4.1.2. Governing Equations ........................................................................................ 32

4.2. Application of TOUGHREACT to Bentonite-Filled EBS and Clay Formation............. 33

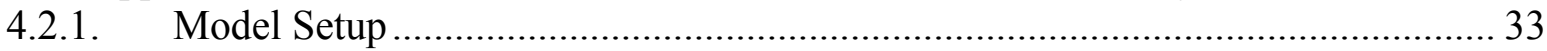

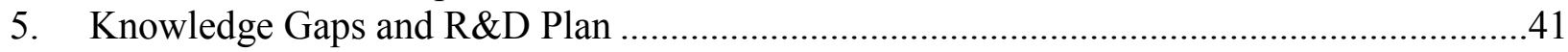

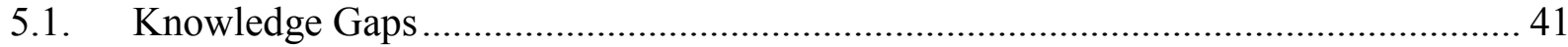

5.2. Research \& Development Plans for Clay/Shale Host Rock ......................................... 43

5.2.1. Near-term R\&D Plans.................................................................................. 43

5.2.2. Longer-term R\&D Plans ............................................................................... 48

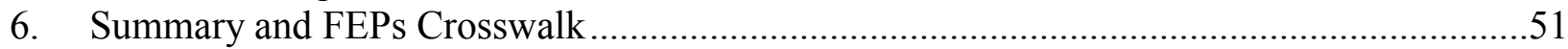

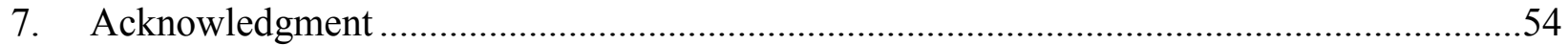

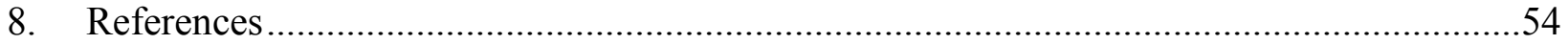




\section{INTRODUCTION}

As a result of the termination of the Yucca Mountain Project, the United States Department of Energy (DOE) has started to explore various alternative avenues for the disposition of used nuclear fuel and nuclear waste. The overall scope of the investigation includes temporary storage, transportation issues, permanent disposal, various nuclear fuel types, processing alternatives, and resulting waste streams. Although geologic disposal is not the only alternative, it is still the leading candidate for permanent disposal. The realm of geologic disposal also offers a range of geologic environments that may be considered, among those clay shale formations. Figure 1-1 presents the distribution of clay/shale formations within the USA.

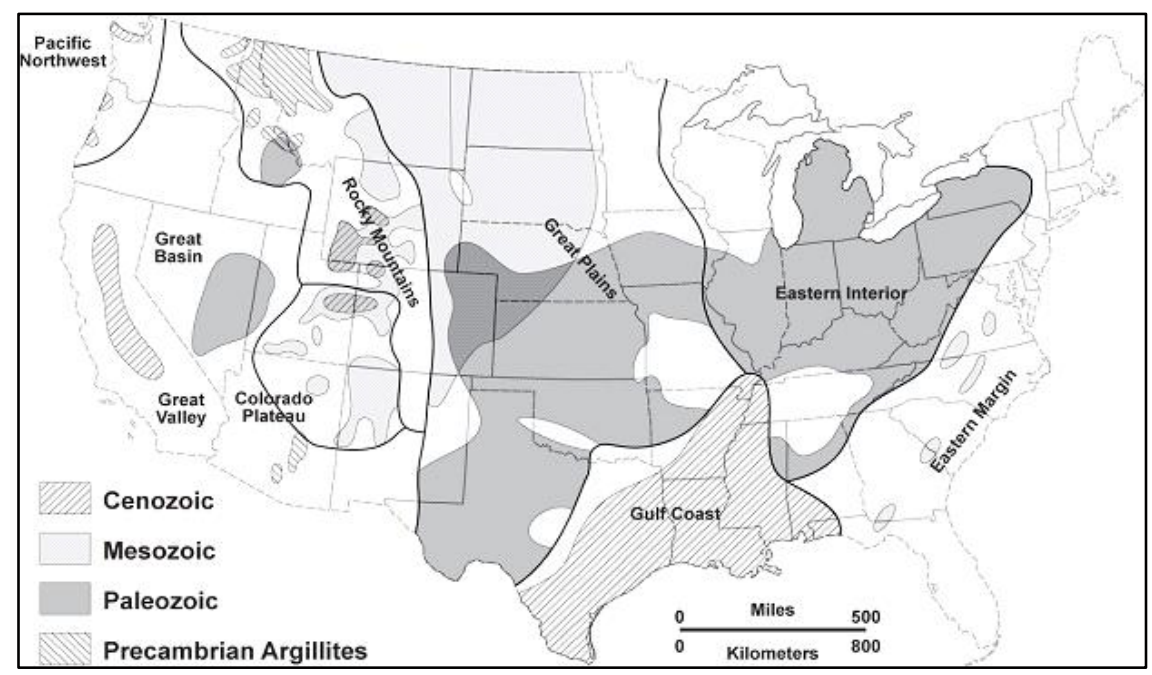

Figure 1-1. Clay/shale-formation distribution in the USA (Gonzales and Johnson, 1984)

Clay rock/shale has been considered as potential host rock for geological disposal of high-level nuclear waste throughout the world, because of its low permeability, low diffusion coefficient, high retention capacity for radionuclides, and capability to self-seal fractures induced by tunnel excavation. For example, Callovo-Oxfordian argillites at the Bure site, France (Fouche et al., 2004), Toarcian argillites at the Tournemire site, France (Patriarche et al., 2004), Opalinus clay at the Mont Terri site, Switzerland (Meier et al., 2000), and Boom clay at Mol site, Belgium (Barnichon et al., 2005) have all been under intensive scientific investigations (at both field and laboratory scales) for understanding a variety of rock properties and their relations with flow and transport processes associated with geological disposal of nuclear waste.

Clay/shale formations may be generally classified as indurated and plastic clays (Tsang et al., 2005). The latter (including Boom clay) is a softer material without high cohesion; its deformation is dominantly plastic. For both clay rocks, coupled thermal, hydrological, mechanical and chemical (THMC) processes are expected to have a significant impact on the long-term safety of a clay repository. For example, the excavation-damaged zone (EDZ) near repository tunnels can modify local permeability (resulting from induced fractures), potentially leading to less confinement capability (Tsang et al., 2005). Because of clay's swelling and shrinkage behavior (depending on whether the clay is in imbibition or drainage processes), 
fracture properties in the EDZ are quite dynamic and evolve over time as hydromechanical conditions change. To understand and model the coupled processes and their impact on repository performance is critical for the defensible performance assessment of a clay repository.

Within the Natural Barrier System (NBS) group of the Used Fuel Disposition (UFD) Campaign at DOE's Office of Nuclear Energy, LBNL's research activities have focused on understanding and modeling such coupled processes. LBNL provided a report in this April on literature survey of studies on coupled processes in clay repositories and identification of technical issues and knowledge gaps (Tsang et al., 2010). This report will document other LBNL research activities within the natural system work package, including the development of constitutive relationships for elastic deformation of clay rock (Section 2), a THM modeling study (Section 3) and a THC modeling study (Section 4). The purpose of the THM and THC modeling studies is to demonstrate the current modeling capabilities in dealing with coupled processes in a potential clay repository. In Section 5, we discuss potential future R\&D work based on the identified knowledge gaps. The linkage between these activities and related FEPs is presented in Section 6.

\section{CONSTITUTIVE RELATIONSHIPS FOR ELASTIC DEFORMATION OF INDURATED CLAY ROCK}

This section presents constitutive relationships for indurated clay rock and demonstrates their usefulness by comparing relevant data sets and our theoretical results. The constitutive relationships refer to relationships among hydraulic, mechanical and other properties. These relationships are the foundation for accurately modeling coupled processes. The development of constitutive relationships builds on a newly proposed stress-strain relationship for elastic deformation of fractured rock (Liu et al., 2009), as well as a concept of internal swelling stress for coal seams that can involve swelling or shrinkage during $\mathrm{CO}_{2}$ sequestration (Liu and Rutqvist, 2010).

\subsection{Stress-strain relationship}

The stress-strain relationship is fundamental for modeling mechanical deformation and the associated coupled processes in porous and fractured rock. Hooke's law, an approximation for small deformations, has been generally used to describe the stress-strain relationship for elastic mechanical processes. It states that the amount by which a material (e.g., rock) body is deformed (the strain) is linearly related to the force (stress) causing the deformation. The current application of Hooke's law to porous and fractured rock is not without questions. Strictly speaking, the proportionality in the observed stress-strain relationship should be constant if the current application of Hooke's law is to be perfectly valid. However, it is nevertheless not unusual to see studies indicating that proportionality is not always constant, but rather stressdependent.

To more accurately model elastic deformation in rocks, Liu et al. (2009) argued that the current application of Hooke's law needs to be improved in several aspects. While the details of their methodology can be found in that paper, we give a brief introduction to their methodology here for the sake of convenience using the volumetric strain (although their results can be easily extended to other types of strains). 
Liu et al. (2009) indicate that in Hooke's law, true strain, rather than engineering strain, should be used, except for a small degree of deformation. (The two strains will be defined later.) Assuming that a uniformly distributed force is imposed on the surface of a homogeneous and isotropic material body subject to elastic deformation, Hooke's law can be expressed as

$$
d \sigma=K d \varepsilon_{v, t}
$$

where $\sigma$ is the hydrostatic stress (the compressive direction is positive), $K$ is bulk modulus, and $\varepsilon_{v, t}$ is the natural or true volumetric strain defined by

$$
d \varepsilon_{v, t}=-\frac{d V}{V}
$$

where $V$ is the total volume of the material body under the current state of stress. In Eqs (2-1) and (2-2), a decrease in the volume is considered to be positive. For a very small degree of deformation, the above strain can be approximated by so-called engineering strain $\left(\varepsilon_{v, e}\right)$ when applying Hooke's law:

$$
d \varepsilon_{v, e}=-\frac{d V}{V_{0}}
$$

where $V_{0}$ is the unstressed bulk volume. When the engineering strain is employed in Hooke's law, one can obtain the following relationship by integrating Eq (2-3) and using the condition that $V=V_{0}$ for $\sigma=0$ :

$$
V=V_{0}\left(1-\frac{\sigma}{K}\right)
$$

Similarly, the use of natural or true strain in Hooke's law (Eq. (2-2)) yields

$$
V=V_{0} \exp \left(-\frac{\sigma}{K}\right)
$$

In the literature of rock mechanics, the engineering strain has been exclusively used considering that the elastic strain is generally small. Porous and fractured rock, however, differs from purely solid materials in that it is inherently heterogeneous and includes both solid phase and pores (and/or fractures) with a variety of geometric shapes. While elastic strain is indeed small in most of the rock volume for stress changes of practical interest, the strain can be considerably larger within some portions of a rock body. For example, some pores (or fractures) in a rock can be subject to significant deformation, and even may completely close under a certain range of stress changes encountered in practice. For these pores, the strain is not small (on the order of one). An accurate description of the deformation of this portion of the rock is important for coupled mechanical and hydrological processes, because fluid flow occurs in these pores and fractures. To deal with this issue, Liu et al. (2009) conceptualize the heterogeneous rock as having two parts, a so called soft part and hard part. Only in the hard part can true strain be approximated by 
engineering strain. This conceptualization can be represented by a hypothesized composite spring system shown in Fig 2-1. Following Liu et al. (2009), we use subscripts $0, e$, and $t$ to denote the unstressed state, the hard part (where engineering-strain-based Hooke's law applies) and the soft part (where natural or true-strain-based Hooke's law must be used), respectively. Then we have

$$
V_{0}=V_{0, e}+V_{0, t}
$$

and

$$
d V=d V_{e}+d V_{t}
$$

Applying Eqs (2-4) and (2-5) to rock volumes $V_{\mathrm{e}}$ and $V_{\mathrm{t}}$, respectively, in Eq (2-7) yields

$$
\begin{gathered}
-\frac{d V}{V_{0}}=\gamma_{e} \frac{d \sigma}{K_{e}}+\gamma_{t} \exp \left(-\frac{\sigma}{K_{t}}\right) \frac{d \sigma}{K_{t}} \\
\gamma_{t}=\frac{V_{0, t}}{V_{0}} \\
\gamma_{e}=1-\gamma_{t}
\end{gathered}
$$

where $K_{e}$ and $K_{t}$ refer to bulk moduli for the hard and soft parts, respectively. The parameters $\gamma_{e}$ and $\gamma_{\mathrm{t}}$ are volumetric portions of hard and soft parts under unstressed conditions. Eqs (2-8)-(210) together comprise the stress-strain relationship proposed by Liu et al. (2009). From that stress-strain relationship (Eq (2-8)), the bulk modulus $K=-V_{0} \frac{d \sigma}{d V}$ is given by

$$
K=\frac{1}{\frac{\gamma_{e}}{K_{e}}+\frac{\gamma_{t}}{K_{t}} \exp \left(-\frac{\sigma}{K_{t}}\right)} .
$$

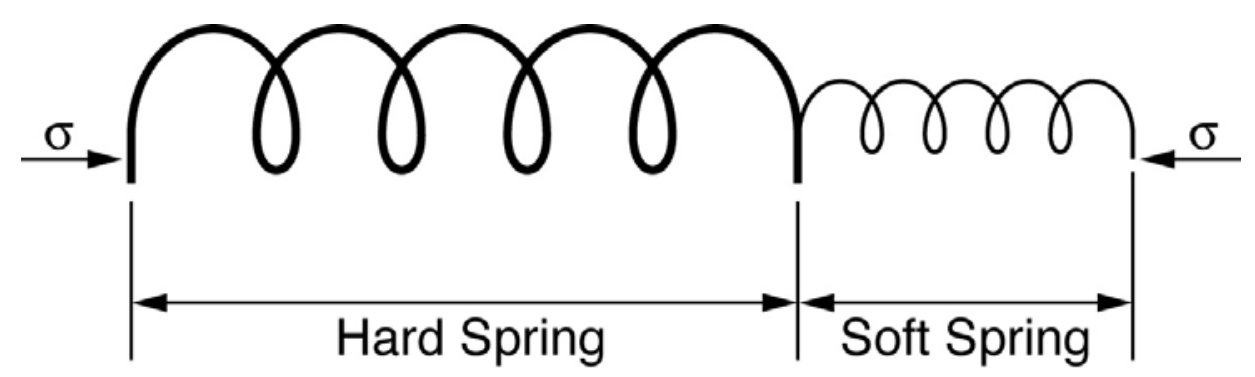

Figure 2-1. A composite spring system consisting of two springs. The hard and soft springs follow engineering-strain-based and true-strain-based Hooke's law, respectively (Liu et al., 2009). 
The validity of the above equation was presented in Liu et al. (2009) for several sandstones. Based on laboratory measurements, Corkum and Martin (2007b) developed an empirical relation for describing the stress dependence of Young's modulus in Opalinus clay. Corkum and Martin (2007a) then performed modeling studies of a mine-by test at the Mont Terri site, Switzerland, and found that a significant portion of the short-term behavior within the damaged zone can be captured using the empirical relation for Opalinus Clay. As a matter of fact, a theoretical relation for such stress dependence is given in Eq (2-11). We will use the data from Corkum and Martin (2007b) to verify Eq (2-11).

\subsection{Stress-dependent hydraulic properties}

Porosity (or aperture for fractures) and permeability are the main stress-dependent hydraulic properties used as key inputs into a coupled hydro-mechanical model.

\section{Rock Porosity}

Using definition of rock porosity $(\phi)$ and using similar notions from Section 2.1, we have

$$
d \phi=\frac{d V^{p}}{V}=\frac{d V_{e}^{p}+d V_{t}}{V}
$$

where $V$ is the bulk volume of porous rock and superscript $p$ refers to pores. (Note that the above equation ignores the effect of $V$ change with stress on porosity change.) For most practical applications of rock mechanics, $V$ can be approximated by the unstressed volume $V_{0}$ for calculating rock porosity. By definition of different volumes, we also have

$$
\begin{gathered}
V_{0}^{p}=V_{0, e}^{p}+V_{0, t} \\
V^{p}=V_{e}^{P}+V_{t}
\end{gathered}
$$

Note that in the above two equations, we consider $V_{t}$ to be a portion of pore volume in a rock body. Following the same procedure used to derive Eqs (2-3) and (2-4), we obtain

$$
d V_{e}^{p}=-C_{e} V_{0, e}^{p} d \sigma
$$

where $C_{e}$ is compressibility for the hard part.

$$
d V_{t}=-\frac{V_{0, t}}{K_{t}} \exp \left(-\frac{\sigma}{K_{t}}\right) d \sigma
$$

Combining Eqs (2-12), (2-15) and (2-16) yields

$$
d \phi=-\phi_{e} C_{e} d \sigma-\frac{\gamma_{t}}{K_{t}} \exp \left(-\frac{\sigma}{K_{t}}\right) d \sigma
$$


where

$$
\phi_{e}=\phi_{0}-\gamma_{t} \text {. }
$$

Integrating $\mathrm{Eq}$ (2-24) and using $\phi=\phi_{0}$ for $\sigma=0$ gives (Liu et al. 2009)

$$
\phi=\phi_{e}\left(1-C_{e} \sigma\right)+\gamma_{t} \exp \left(\frac{\sigma}{K_{t}}\right) .
$$

where $C_{e}$ is the compressibility for the hard fraction of pore volume. This treatment is based on our argument that the entire soft part corresponds to some fraction of pore volume. Once porosity is known, permeability for a rock matrix can be estimated based on relationships between permeability and porosity. Eq (2-19) was validated using data from sandstones (Liu et al., 2009). At this point, measured porosity as a function of stress seems not to be available yet for clay rock considered for hosting a geological repository of nuclear waste. However, Eq (2-19) was derived from $\mathrm{Eq}(2-8)$, and the verification of the latter may be considered as indirect verification of the former.

\section{Fracture aperture and permeability}

In this subsection, we present a formula for the dependence of fracture aperture on normal stress based on the stress-strain relationship given in Section 2.1. Consider a fracture to be embedded into a rock sample subject to normal stress $\sigma_{n}$. We again divide fracture space into "hard" and "soft" parts along the direction normal to the fracture plane. Then, the volumetrically averaged fracture aperture (b) is given by

$$
b_{0}=b_{0, e}+b_{0, t}
$$

under unstressed conditions, and

$$
b=b_{e}+b_{t}
$$

under stressed conditions. Similar to previous sections, subscripts $e$ and $t$ (for "engineering" and "true," respectively) refer to the "hard" and "soft" parts in a fracture. Hooke's law for the two parts can be expressed by

$$
\begin{aligned}
& d \sigma_{n}=-K_{F, e} \frac{d b_{e}}{b_{0, e}} \\
& d \sigma_{n}=-K_{F, t} \frac{d b_{t}}{b_{t}}
\end{aligned}
$$

where subscript $\mathrm{F}$ refers to the fracture. (For convenience, the volumetric strain will not be used here.) Note that the stress in the above two equations refers to far-field normal stress, rather than local stress. 
Combining Eqs (2-22) and (2-23) gives

$$
d b=d b_{e}+d b_{t}=-b_{0, e} \frac{d \sigma_{n}}{K_{F, e}}-b_{t} \frac{d \sigma_{n}}{K_{F, t}} .
$$

Integrating the above equation and using $\mathrm{Eq}(2-20)$ and the following relationship obtained from Eq (2-23):

$$
b_{t}=b_{0, t} \exp \left(-\frac{\sigma_{n}}{K_{F, t}}\right)
$$

one arrives at (Liu et al. 2009)

$$
b=b_{0, e}\left(1-\frac{\sigma_{n}}{K_{F, e}}\right)+b_{0, t} \exp \left(-\frac{\sigma_{n}}{K_{F, t}}\right)
$$

Because fracture permeability is proportional to the cube of fracture aperture, the fracture permeability $\mathrm{k}$ is given by

$$
\left(\frac{k}{k_{0}}\right)^{1 / 3}=\frac{b_{0, e}}{b_{0}}\left(1-\frac{\sigma_{n}}{K_{F, e}}\right)+\frac{b_{0, t}}{b_{0}} \exp \left(-\frac{\sigma_{n}}{K_{F, t}}\right)
$$

where $k_{0}$ is the permeability corresponding to $b_{0}$.

$$
\left(\frac{k}{k_{0}}\right)^{1 / 3}=\exp \left(-\frac{\sigma_{n}}{K_{F, t}}\right)
$$

The above equation essentially assumes that the entire fracture aperture is "soft." Given the fact that clay rock is generally viewed as soft rock, it seems logical to use Eq (2-28) for fractures in clay rock. This is supported by a number of laboratory measurements that show linear relationships between the log of measured fracture permeability and stress (e.g., Blumling et al., 2007; Zhang and Rothfuchs, 2008; Popp et al., 2008). However, data reported by Jobmann et al. (2010) seem to indicate that permeability relationships are better represented by a curve similar to that with $b_{r}>0$. For simplicity, we focus on Eq (2-28), which seems to be reasonable for most clay studies reported in the literature, while Eq (2-27) may be employed for more general cases. 


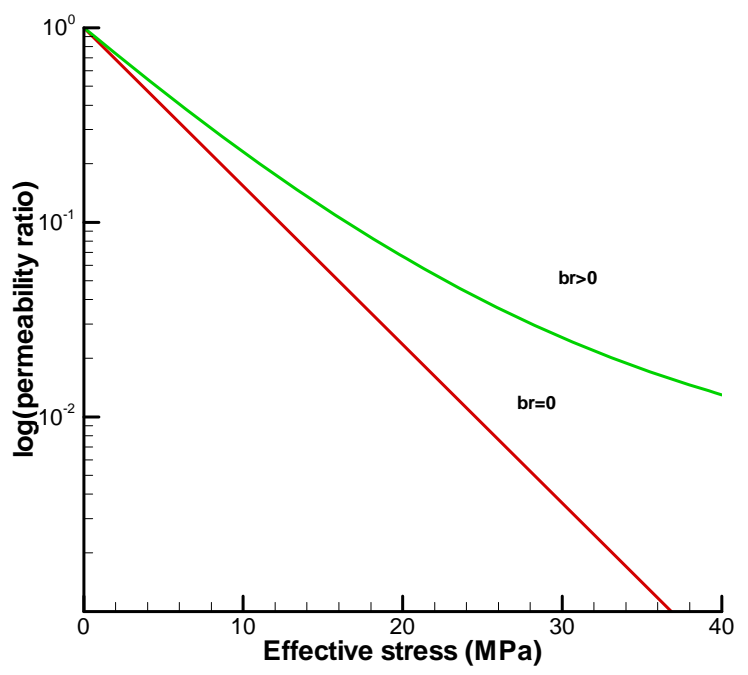

Figure 2-2. Log of fracture permeability as a function of stress (Eq (2-27)). The $b_{r}$ denotes the first term on the right hand side of Eq (2-27).

\subsection{Effective stress for fractures involving rock swelling}

In all the above discussions, stress refers to effective stress. It is relatively straightforward to deal with the effective stress for clay rock matrix involving swelling. The treatment is essentially the same as handling volume changes in the rock matrix owing to temperature changes (e.g., Jaeger et al., 2007). However, some special consideration needs to be given to fractures when swelling processes are involved. To do so, some methodology developed for estimating coal permeability is adopted here (Liu et al., 2010). Coal will swell when absorbing $\mathrm{CO}_{2}$ during the $\mathrm{CO}_{2}$ geological sequestration.

Based on Biot's theory, the effective stress is defined as (Jaeger et al., 2007)

$$
\sigma=\sigma_{t}-\alpha P
$$

where $\sigma_{\mathrm{t}}$ is total stress, $P$ is fluid pressure, and $\alpha$ is Biot's coefficient. Note that compressive stress is here considered positive. Following previous studies (e.g., Gray, 1987; Shi et al., 2004), the Biot's coefficient is considered to be one in this study, although our theoretical development allows for arbitrary coefficient values.

For clay rock containing an infinite fracture (generally assumed for modeling flow and transport in fractured rock), matrix swelling will not affect fracture permeability under the constant confining (total) stress conditions commonly used in laboratory measurements, because the effective stress defined in Eq. (2-29) is independent of the matrix swelling, as a result of the complete separation between matrix blocks coursed by through-going fractures. In this case, for a given pressure $P$, the swelling will result in increasing fracture spacing rather than changes in fracture aperture. 
In reality, clay matrix blocks are not completely separated from each other by fractures. Figure 2-3 shows a simplified horizontal cross section of a clay rock with two adjacent vertical fractures, separated by a clay-matrix "bridge" that connects matrix blocks on the different sides of fractures. During matrix swelling, fractures are compressed, because they are weak and soft structures within the rock, and therefore an additional force (corresponding to stress $\sigma_{I}$ ) will be imposed on the fractures. At the same time, the matrix bridge is subject to an additional force in the opposite direction to $\sigma_{I}$. If these two forces are completely balanced, fractures will be subject to this additional stress $\sigma_{I}$, while confining stress remains unchanged. Because this stress largely results from internal structures (or the connectivity of matrix blocks) within clay rock and can be internally balanced under constant confining stress conditions, it is called "internal swelling stress". In this case, the effective stress for fractures should be given as

$$
\sigma=\sigma_{t}-\alpha P+\sigma_{I}
$$

Note that $\sigma_{I}$ is positive for matrix swelling and negative for matrix shrinkage. The concept of "internal swelling stress" was first put forward by Liu and Rutqvist (2010) who derived a similar effective stress equation for coal seams associated with swelling.

The concept of internal swelling stress implies that coal-matrix strain resulting from swelling $\left(\varepsilon_{s}\right)$ can be divided into two parts:

$$
\varepsilon_{s}=\varepsilon_{s B}+\varepsilon_{s I}
$$

where $\varepsilon_{S I}$ is the strain corresponding to the internal swelling stress, and $\varepsilon_{S B}$ is the strain contributing to the bulk strain in fractured clay generally measured in the laboratory. It is $\varepsilon_{S I}$ (a portion of $\varepsilon_{S}$ ) that results in fracture permeability (or aperture) changes under constant confining stress conditions.

The relationship between $\varepsilon_{S}$ and $\varepsilon_{S I}$ may be a complex function of matrix block connectivity within clay rock and other relevant factors. As a first approximation, following Liu and Rutqvist (2010), we assume the ratio between the two strains to be a constant:

$$
\varepsilon_{s I} \approx f \varepsilon_{s}
$$

where $f$ is a value between zero and one and determined from measurements. This treatment will be evaluated against laboratory test results below - we acknowledge that more studies may be needed to develop more rigorous relationships between $f$ and other properties in the future. Based on Hooke's law, $\sigma_{I}$ can be related to swelling strain by

$$
\sigma_{I}=f \varepsilon_{s} K_{M}
$$

where $K_{M}$ is the bulk modulus for clay matrix and can be stress dependent (Eq. (2-11)). 


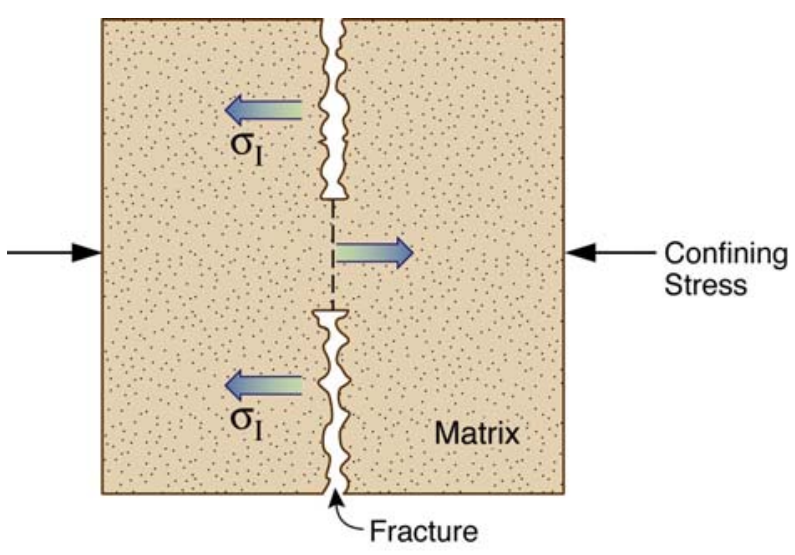

ESD08-041

Figure 2-3. A schematic description of internal swelling stress (Liu et al., 2010). The arrows correspond to stresses imposed on the left part of the rock as a result of swelling.

\subsection{Data Analyses}

Some key constitutive relationships for elastic deformation of clay rock are presented in the above sections. The current section will demonstrate the validity of these relationships by comparing the theoretical results with selected laboratory measurements, with a focus on examining whether the constitutive relationships can satisfactorily match the observations and explain the related processes.

\section{Stress-Strain data of Opalinus clay}

Corkum and Martin (2007) reported comprehensive laboratory measurements for the mechanical behavior of Opalinus clay (with a water content of 6.1\%) at low stress. The low-stress behavior is of interest because it is closely associated with unloading around tunnels and the resultant excavation damaged zone. A number of uniaxial and triaxial compression tests were performed, indicating significant nonlinear elastic deformation in the low stress region. Cokum and Martin (2007) suggest that the nonlinear behavior can be explained from clay's micro-structure, associated with diagenetic processes over the last 180 million years.

We use uniaxial test results to verify our stress-strain relation (Eq. (2-11)). To do so, we need to replace volumetric strain with axial strain, and bulk modulus $(K)$ with the corresponding Young's modulus $(E)$ in Eq (2-11). The test results are given as axial stress as a function of axial strain (Fig. 2-4). To avoid (as much as possible) the non-uniqueness of parameter values determined from curve fitting, we use a simple procedure to estimate parameter values from porosity versus confining pressure data. As shown in Figure 2-4, measured relations between stress and strain are very well represented by a straight line for relatively high stresses. The slope of the straight line is used to determine $\frac{E_{e}}{\gamma_{e}}$ because the second term in the denominator of Eq (2-11) is negligible for high stress values. The strain value at the intersection between the straight line and the strain axis in Figure 2-4 gives the $\gamma_{t}$ value, considering that the straight line represents the first term in the denominator of Eq (2-11). The above procedure allows for direct 
determination of values for $E_{e}, \gamma_{\mathrm{e}}$, and $\gamma_{t}$. The remaining parameter $E_{t}$ can be estimated using a data point at relatively low pressures. As indicated in Fig 2-4, the data are in excellent agreement with our theoretical results for samples BRA 2-2A, BRA 1-3A and BRA 1-3B. These samples are taken from boreholes BRA-1 and BRA-2 drilled at the Mont Terri site, Switzerland. Fitted parameter values are given in Table 2-1.

Table 2-1. Fitted mechanical parameters for Opalinus clay

\begin{tabular}{|l|l|l|l|}
\hline Rock Sample & \multicolumn{1}{|c|}{$\gamma_{\mathrm{t}}(\%)$} & \multicolumn{1}{|c|}{$E_{e}(\mathrm{MPa})$} & \multicolumn{1}{c|}{$E_{t}(\mathrm{MPa})$} \\
\hline BRA 2-2A & 0.22 & 2494.5 & 0.22 \\
\hline BRA 1-3A & 0.13 & 2596.6 & 0.38 \\
\hline BRA 1-3B & 0.08 & 3097.6 & 0.65 \\
\hline
\end{tabular}

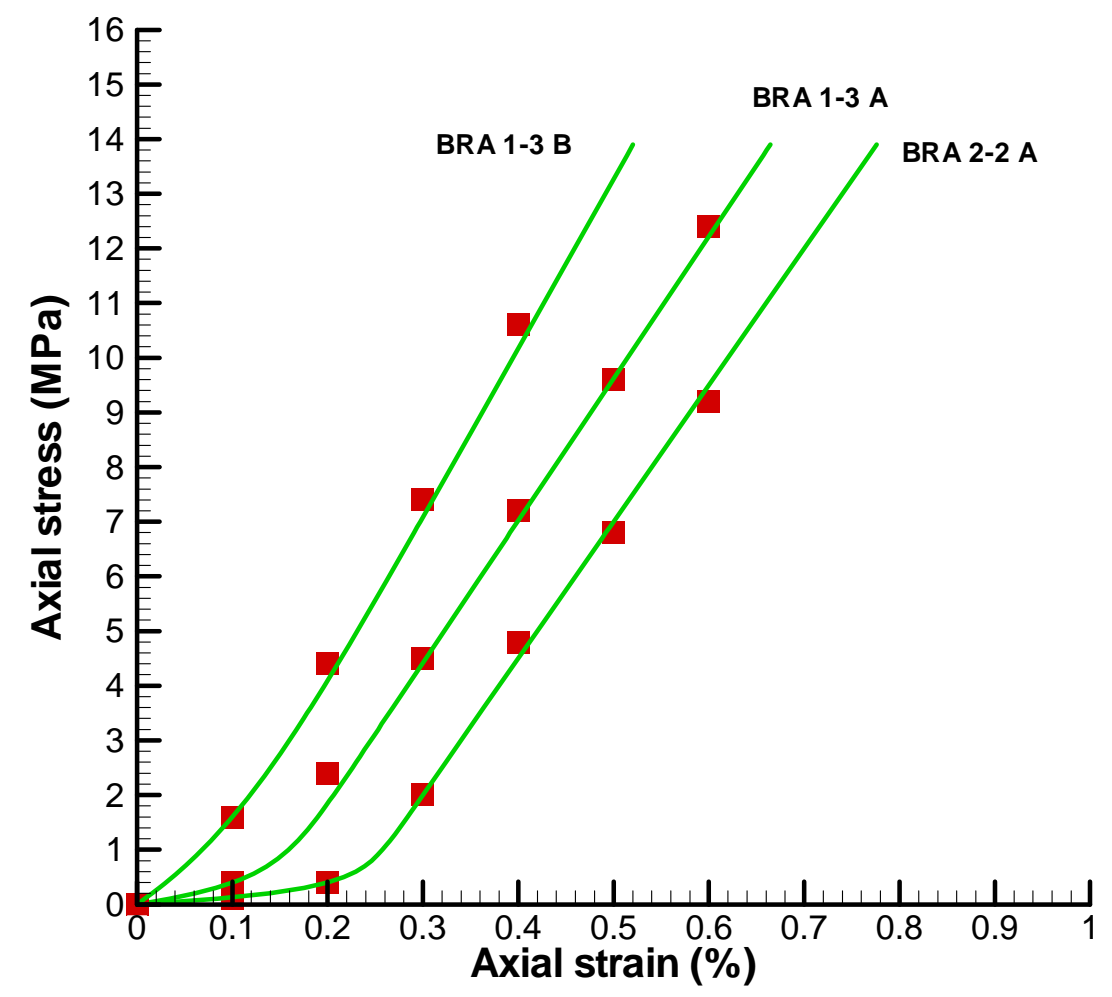

Figure 2-4. Comparison between laboratory measurements and values calculated using Eq (2-11) in which volumetric strain and a bulk modulus $(K)$ need to be replaced with axial strain and the corresponding Young's modulus $(E)$, respectively. The data points are measurements (Corkum and Martin, 2007) and the solid curves are theoretical results. 


\section{Water permeability measurements for a macro-cracked argillite sample}

Recently, Davy et al. (2007) reported on laboratory measurements of single fractures within macro-cracked Callovo-Oxfordian argillite samples subject to both confinement and waterinduced swelling. The data set provides a unique opportunity to examine our formulations for estimating fracture permeability as a function of effective stress that considers effects of swelling.

For water permeability tests, the experimental procedure was designed so as to apply an initial continuous fluid flow through the fracture, and then to superimpose an additional pulse flow for permeability measurements made at each confining pressure level, either right after loading or after several hours at a given confining pressure (the total stress), or right after unloading. For all of the tests, visual a posteriori inspection of water permeability samples showed very limited water penetration in the argillite sample bulk. Fig. 2-5 shows the test procedure in terms of changes in confining pressure and fracture closure for Sample 2 (Davy et al., 2007). Although water permeability measurements were provided for two samples (samples 2 and 5) in Davy et al. (2007), we will analyze test results for Sample 2 only in this study, because Sample 2 is subject to a more complex test procedure (Fig 2-5). For a given confining pressure, the fracture closure increases from point 1 to 2 , which cannot be explained based on elastic deformation and is very likely due to water-induced plastic deformation at the beginning of the test. Therefore, our analysis will focus on data points after Point 2. We also assume elastic deformation in that data range - mainly justified by the fact that our analysis based on the elastic deformation seems to be able to explain the majority of experimental observations. Also note that our Fig 2-5 is identical to Fig 10(b) in Davy et al. (2007), except that we renumbered the chronological order of points such that they are consistent with those in Fig 12 of Davy et al. (2007), which presents fracture permeability as a function of confining pressure (Catherine A. Davy, Personal communication). 


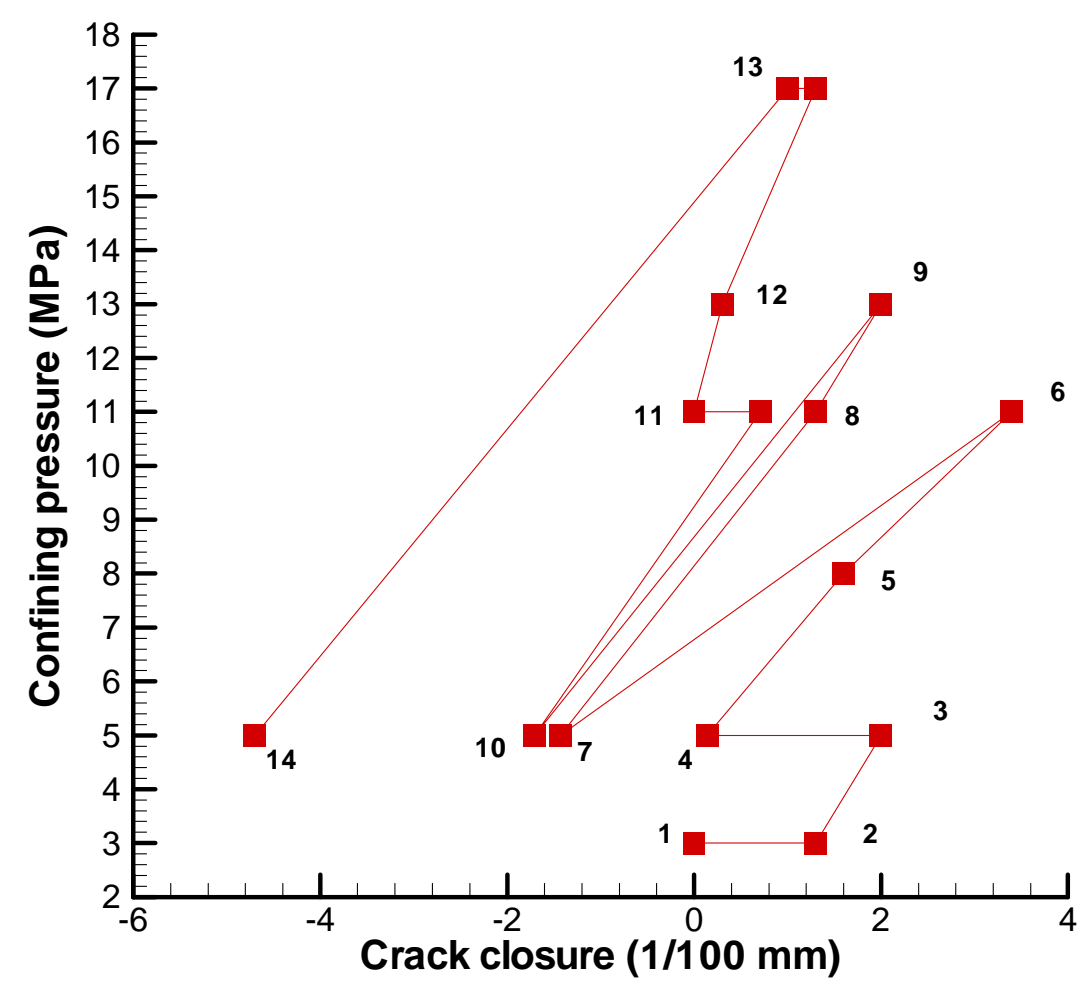

Figure 2-5. Test procedure of water permeability measurement (in terms of confining pressure and fracture [crack] closure) for sample 2 of Davy et al. (2007). The numbers in the figure indicate the chronological order of points (Catherine A. Davy, Personal communication).

In Fig 2-5, points 3, 4, 7, 10 and 14 correspond to the same confining pressure but with different amounts of swelling (measured as difference in crack closure between a given point and Point 3 ). We believe that it is largely due to the transient behavior of water flow from fractures into the rock matrix. A longer time corresponds to a larger water penetration depth into the rock matrix near the fracture, and therefore to a larger rock volume involving swelling. Note that during the water permeability measurement, water was injected into the fracture. For simplicity, we assume that water penetration depth as a function of time can be described by the well-known infiltration theory developed by Philip (1957). Under ponding conditions on the ground surface, Philip's theory indicates that the cumulative amount of water infiltrating into unsaturated soil with a uniform initial water saturation is proportional to the square root of time. Consequently, if we view the fracture wall as the ground surface, then approximate the water penetration depth by the amount of accumulative infiltrating water (in depth) divided by the difference between saturated and initial water contents, and further assume that swelling within the water-penetrating zone is uniform and occurs simultaneously once water content is increased, then the total swelling, S, will be proportional to water penetration depth, or

$$
S=A t^{1 / 2}
$$

where $A$ is a constant herein. The above equation (with $A=3.08 \mathrm{E}-2 \mathrm{~mm} / \mathrm{d}^{-1 / 2}$ ) seems to fit observed swelling for Points 3, 4, 7, 10, and 14 (corresponding to different times) satisfactorily (Fig 2-6), indicating that our above reasoning is reasonable. Note that the observed crack-closure value in Davy et al. (2007) is a combination of rock swelling and the corresponding change in 
fracture aperture. However, as a result of the low water permeability of fracture, the fracture aperture value (estimated from cubic law) is negligibly small, only on the order of $1 \mathrm{E}-3 \mathrm{~mm}$. Therefore, in this study, the swelling is approximated by the observed crack closure.

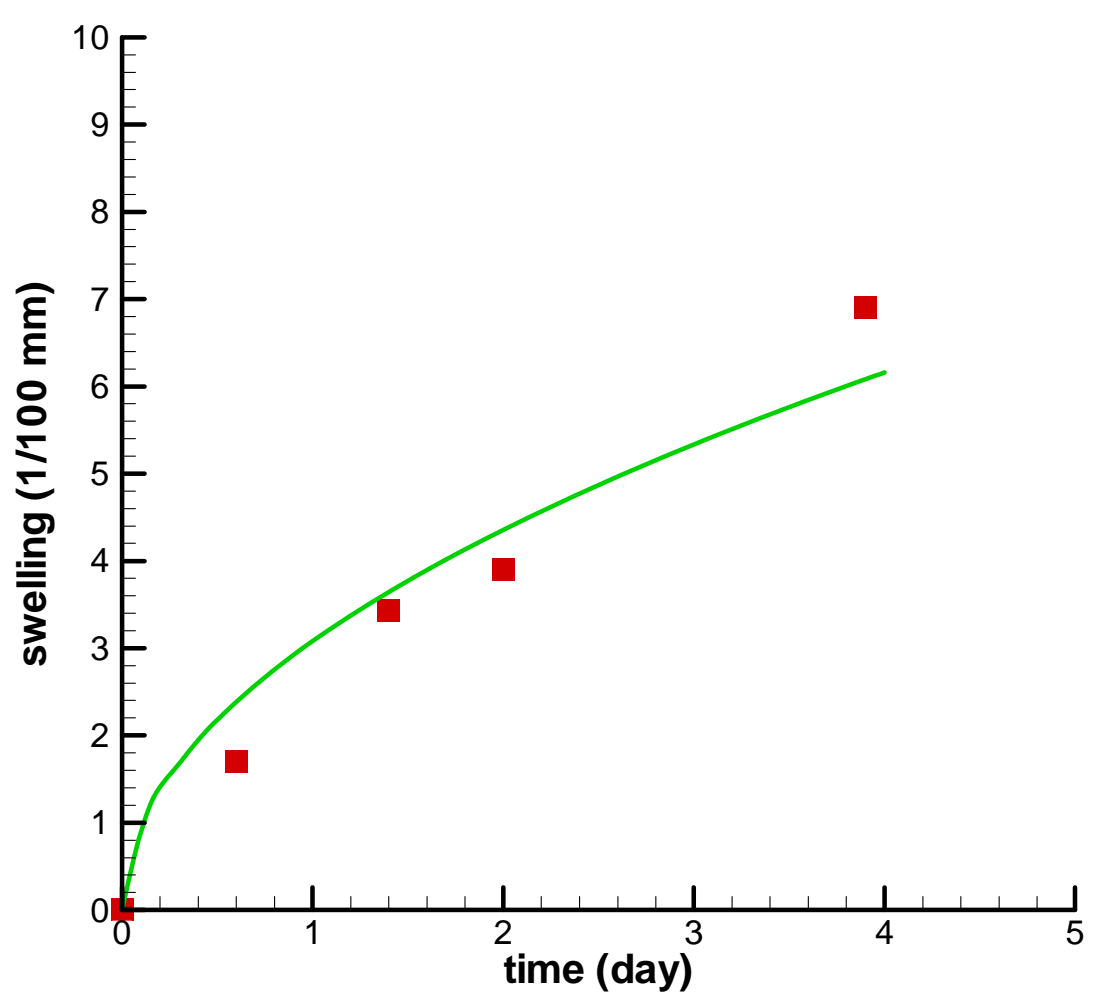

Figure 2-6. Comparison of observed swellings for points $(3,4,7,10$, and 14) with those calculated from Eq (2-34) (solid curve). The fitted $A$ value is $0.68 \mathrm{~d}^{-1 / 2}$.

When confining and pore pressures are constant, fracture permeability purely due to swelling may be obtained from Eqs (2-28) and (2-30) and given as

$$
\left(\frac{k}{k_{3}}\right)^{1 / 3}=\exp \left(-\frac{\Delta \sigma_{I}}{K_{F, t}}\right)
$$

where $\mathrm{k}_{3}$ is the permeability at Point 3 and $\Delta \sigma_{I}$ is the difference in internal swelling pressure between a given point and Point 3. Using definition of the internal swelling stress (Eq. (2-32)) together with Eq. (2-34), the difference in internal swelling pressure is given as

$$
\Delta \sigma_{I}=f \mathcal{E}_{s} K_{M}=f K_{M} \frac{S}{L}=\left(\frac{f K_{M} A}{L K_{F, t}}\right) K_{F, t} t^{1 / 2}=B K_{F, t} t^{1 / 2}
$$

where L is fracture spacing (approximated by the rock-sample's radius in Davy et al. (2007)), and $B$ is a constant. Combining Eqs. (2-35) and (2-36) yields 


$$
\left(\frac{k}{k_{3}}\right)^{1 / 3}=\exp \left(-B t^{1 / 2}\right)
$$

Again, Eq. (2-37) fits the observations fairly well.

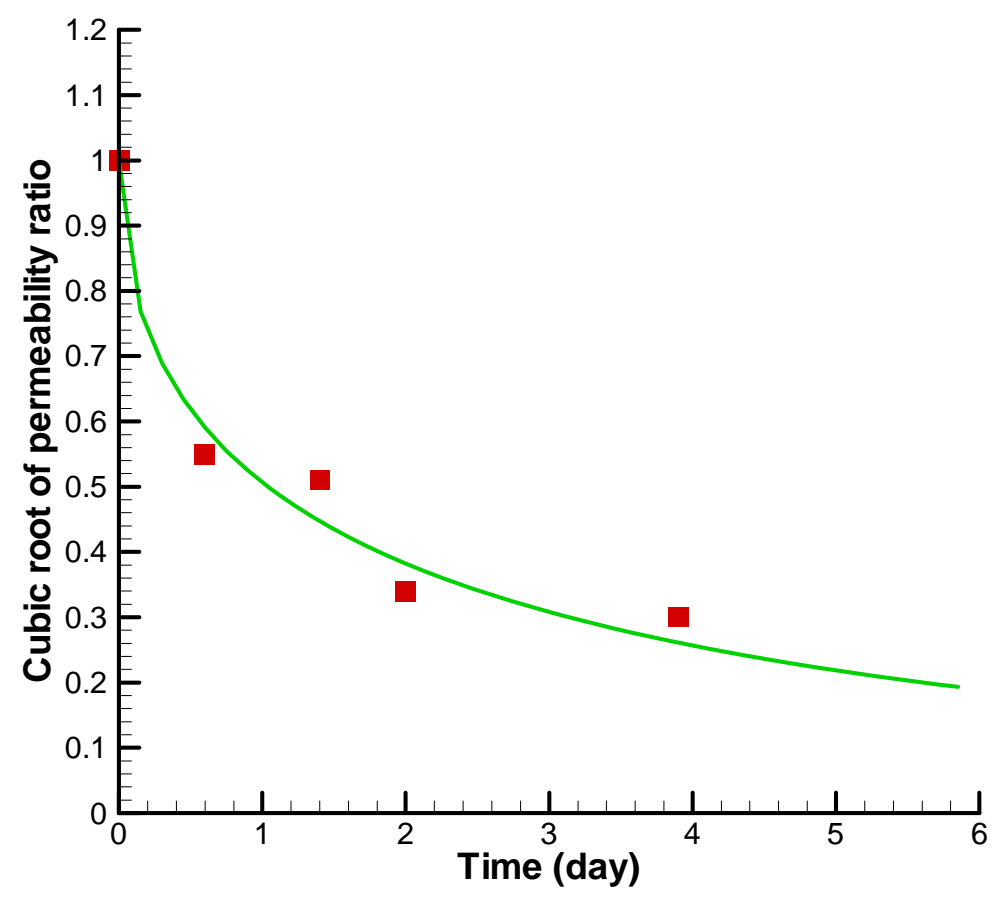

Figure 2-7. Match between observed values for $\left(\mathrm{k} / \mathrm{k}_{3}\right)^{1 / 3}$ for points $(3,4,7,10$ and 14) with those calculated from Eq. (2-37) (solid curve).

Eq. (2-37) is applicable only when confining pressure (or total stress) and the pore pressure of water in the fracture is constant. In this study, we assume that pore pressure changes can be ignored compared to the much larger changes in confining pressure in the water permeability experiments of Davy et al. (2007). This can be justified by the observation that fracture permeability changes are mainly determined by confining pressure and swelling (Davy et al., 2007). In this case, a more general permeability relationship (that considers the effects of both confining pressure and swelling) can be obtained by combing Eqs (2-28), (2-30) and (2-37):

$$
\left(\frac{k}{k_{3}}\right)^{1 / 3}=\exp \left(-\frac{\Delta \sigma_{t}}{K_{F, t}}-B t^{1 / 2}\right)
$$

The only unknown in the above equation is $K_{F, t}$ which can be estimated from the permeability data as a function of both confining pressure and time (Davy et al., 2007). We are especially interested in whether Eq. (2-38) is sufficient to represent the data. The estimated (or fitted) $\mathrm{K}_{\mathrm{F}}$ is $16 \mathrm{MPa}$. Fig 2-8 shows a comparison between measured and estimated permeability values as a function of time. Note that for a given time in Fig 8, there are two data points corresponding to the observed and estimated values, respectively. Given the complexity of the experimental 
processes, the comparison is remarkable, supporting the validity of the relevant constitutive relationships. To further examine the usefulness of our generalized effective stress (Section 2.3), Fig 2-9 shows $\left(k / k_{3}\right)^{1 / 3}$ as a function of difference of effective stress (between a given point and Point \#3) calculated by

$$
\Delta \sigma=\Delta \sigma_{t}+\Delta \sigma_{I}=\Delta \sigma_{t}+K_{F, t} B t^{1 / 2}
$$

Based on Eqs (2-27) and (2-29), the $\log$ of $\left(\mathrm{k} / \mathrm{k}_{3}\right)^{1 / 3}$ is a linear function of the difference in effective stress given in the above equation. Again, the data supports our theoretical results, as shown in Fig 2-9.

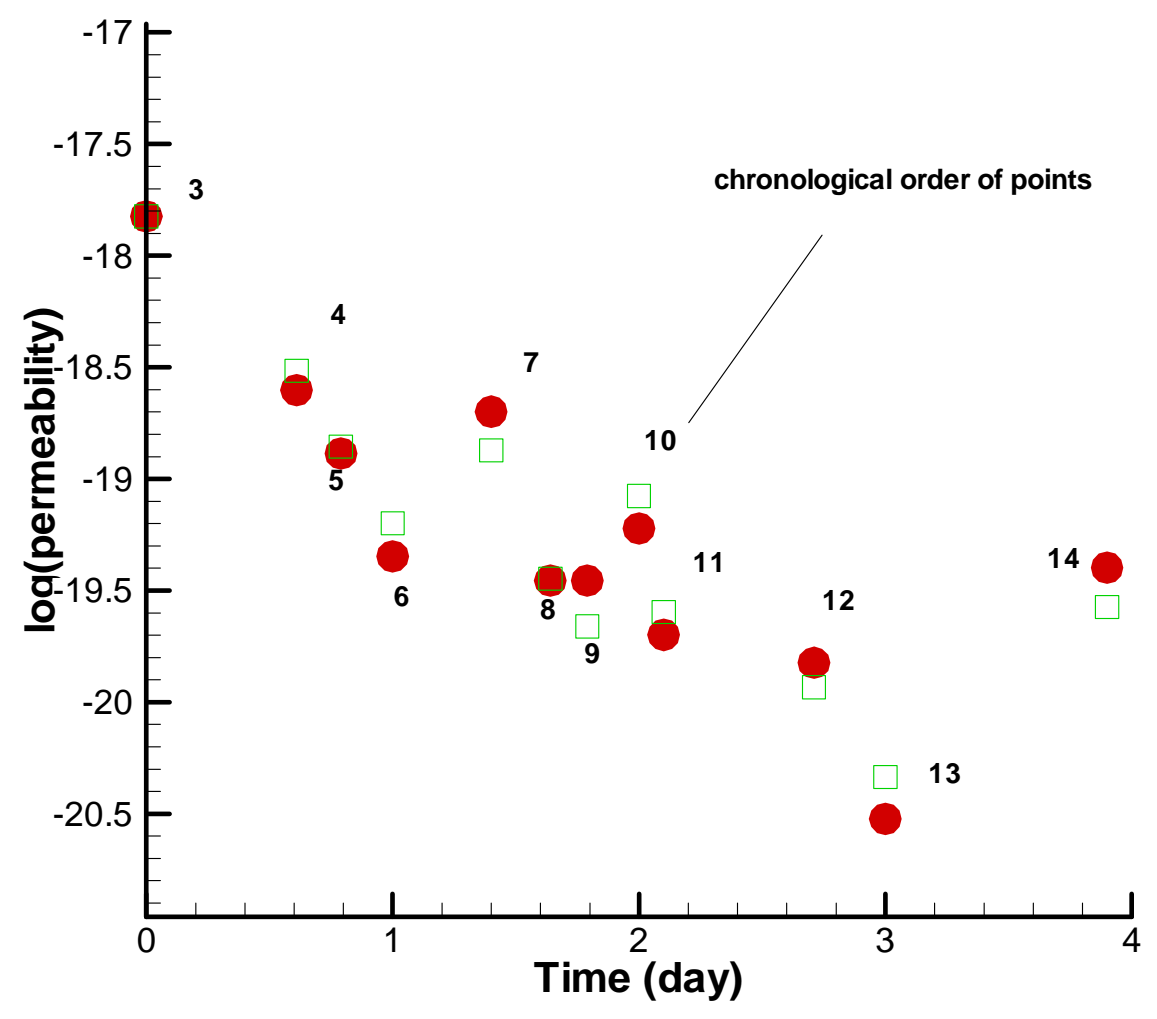

Figure 2-8. Comparisons between observed and simulated fracture permeability changes as a function of time. The solid circles are measurements. 


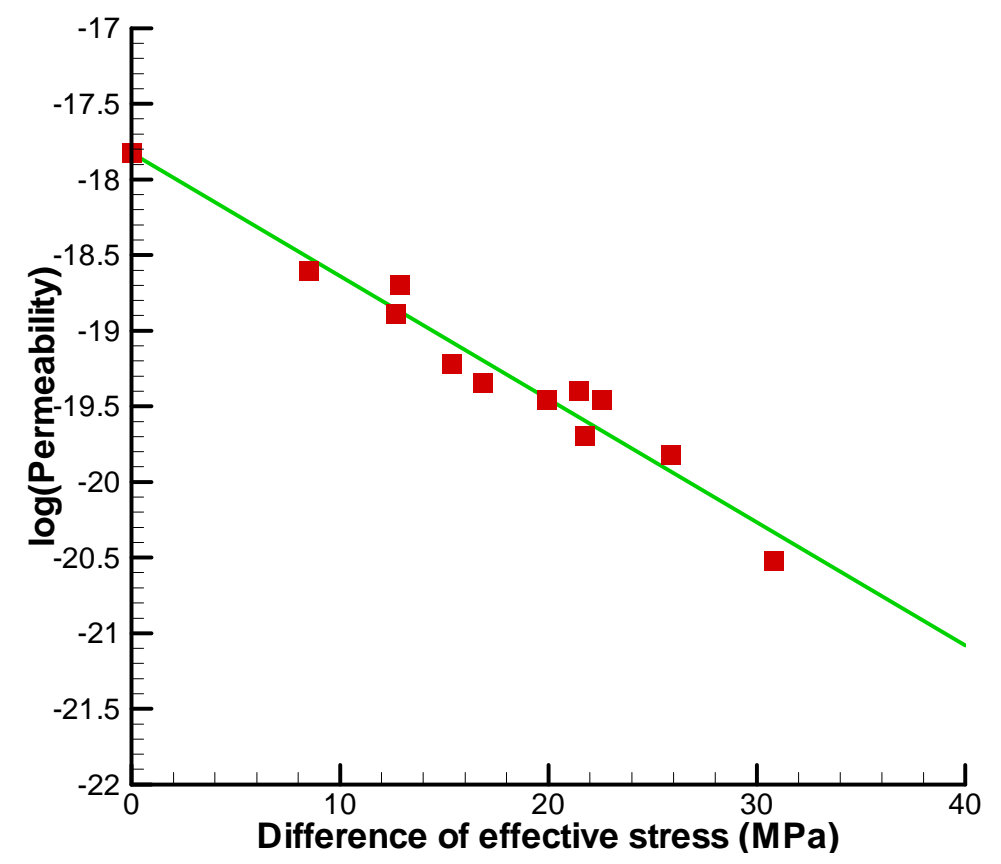

Figure 2-9. Comparisons between observed and simulated relationships between log of permeability and the difference in effective stress defined in Eq (2-39). The data points are measurements.

Finally, it is important to indicate that we ignore creeping processes in our data analysis, based on the consideration that permeability changes due to creeping are not expected to be significant in the experiments of Davy et al. (2007). For example, the laboratory experiments of Jobmann et al. (2010) showed that over about 5 days, fracture permeability was reduced by $20 \%$ only for Opalinus clay. This permeability change is much smaller than those observed in the experiments of Davy et al. (2007) (Figure 2-8), although Opalinus clay is softer than the Callovo-Oxfordian argillite rock studied in Davy et al. (2007) and therefore subject to a larger degree of creeping.

\subsection{Summary and Directions of Future Research}

In this study, we proposed several important constitutive relationships for indurated clay rock. This work is based on three recently developed concepts (or theories). First, when applying Hooke's law in clay rocks, true strain (rock volume change divided by the current rock volume), rather than engineering strain (rock volume change divided by unstressed rock volume), should be used, except when the degree of deformation is very small. In the latter case, the two strains will be practically identical. Second, because of its inherent heterogeneity, clay rock can be divided into two parts, a hard part and a soft part, with the hard part subject to a relatively small degree of deformation compared to the soft part. Third, for swelling rock like clay, the effective stress needs to be generalized to include an additional term resulting from the swelling process. To evaluate our theoretical development, we analyzed uniaxial test data for core samples of Opalinus clay and laboratory measurements of single fractures within macro-cracked CallovoOxfordian argillite samples subject to both confinement and water-reduced swelling. The focus of this was to test whether our constitutive relationships can adequately represent the data and explain the related observations. Given the nonlinearity and complexity shown in the data, the 
agreement between our theoretical results and data is remarkably reasonable, supporting the validity of our proposed constitutive relationships.

The results of this preliminary research leads to the following important outstanding questions which will need to be addressed in FY11 and beyond:

- What is modified Hooke's law for anisotropic stress conditions?

- How can we include the effects of moisture-dependent mechanical properties?

- What are generalized constitutive relationships when damage and plastic deformation are important?

- How can we deal with constitutive relationships for rock mass in EDZ that includes both fractures and matrix?

- How can we incorporate effects of chemical and thermal processes on swelling?

In future studies, the development of constitutive relationships will also be integrated with numerical simulations of coupled processes.

\section{THM MODELING IN CLAY/SHALE ENVIRONMENTS}

This section provides a review of current LBNL modeling capabilities available for studying coupled THMC processes and reactive transport in clay/shale host rock materials. This review intends to help plan UFD modeling activities with the current existing capabilities and also to help identify needs to improve these capabilities for future research activities.

\subsection{Modeling Tools for Coupled THM processes}

For the past decade, LBNL has been active in the development and application of coupled thermal-hydrological-mechanical (THM) modeling of bentonite-clay and rock systems associated with geological disposal of spent nuclear fuel. As part of this effort, LBNL has since 1992 been involved as a research team in the international collaborative project DECOVALEX (Development of COupled Models and their VALidation against EXperiments in nuclear waste isolation). The modeling of THM processes in expansive (swelling) clay used as a buffer in most current disposal concepts in Europe, Asia and Canada, has been conducted using LBNL's ROCMAS finite element code. More recently, through the work within the Yucca Mountain Project, LBNL has developed an alternative model called TOUGH-FLAC, which is based on linking LBNL's TOUGH family multiphase flow codes to the commercial FLAC $^{3 \mathrm{D}}$ geomechanical code. The development of the ROCMAS and TOUGH-FLAC has always been driven by needs for solving field-scale, multiyear in situ experiments of EBS and rock systems, including

1) The Kamaishi Mine heater test, Japan

2) The FEBEX in situ experiment at the Grimsel Test Site, Switzerland

3) The Drift Scale Test at Yucca Mountain, Nevada 
4) The Tunnel Sealing Experiment (TSX) at URL Canada

5) The French Tournemire site in indurate clay.

A large number of Bench Mark Tests (BMTs) have been simulated, focusing on long-term coupled THM processes, both in the near field and EBS of multiple-barrier nuclear waste repositories and in the surrounding rocks. These cases include ROCMAS and TOUGH-FLAC modeling of:

1) The Japanese H12 repository design with vertical deposition holes.

2) The proposed high-level nuclear waste repository in Sweden for the KBS-3 concept.

3) The Canadian conceptual design for a repository in granite with horizontal deposition tunnels.

4) The Spanish EBS system emplaced in granite with horizontal deposition tunnels.

Moreover, a large number of laboratory experiments have been simulated for model validation as well as for calibration of coupled THM properties.

\subsubsection{The ROCMAS Code}

The ROCMAS code (ROCk Mass Analysis Scheme) is a finite-element code for analysis of coupled THM processes in saturated-unsaturated fractured porous media. It has been gradually developed and extended since the early 1980s, headed by J. Noorishad at the LBNL. A hydromechanical formulation for fractured rock, based on Biot's general effective stress theory (Biot, 1941), was first developed, and a nonisothermal version of ROCMAS was presented in Noorishad et al., (1984). While at the time numerical models existed for coupled THM processes in porous media, the ROCMAS code was probably the first for fractured rocks, to include discrete fractures with non-linear coupled hydraulic and geomechanical behavior. The formulation was further extended from fully saturated to partially saturated media by Noorishad and Tsang (1996) and thereafter in Rutqvist et al. (2001), completing the formulation regarding the heat equation and effects of grain compressibility implemented into a full three-dimensional version.

In ROCMAS, the formulation of coupled thermo-hydroelasticity in terms of Biot's theory of consolidation (Biot, 1941) is extended to partially saturated media through Philip and de Vries' (1957) theory for heat and moisture flow in soil. In this theory, three phases (solid, liquid, and gas) are present. However, it is assumed that the gas pressure $P_{g}$ is constant and equal to atmospheric pressure throughout the porous medium. As a consequence, vapor transport occurs only through molecular diffusion driven by a gradient in vapor concentration (density), while advection of vapor with bulk gas flow is neglected. The vapor density in the medium is governed by Kelvin's relation, assuming thermodynamic equilibrium for pore liquid in contact with its vapor, and phase transitions occur as evaporation-condensation processes. During heat transfer, coexisting fluid and solid components are assumed to be in local thermal equilibrium (i.e., locally they are at the same temperature). The mechanical behavior of the porous media consists of the gas, liquid and solid-matter responses to local pressure and the overall material (skeleton) response to effective stresses. Fractures are treated as a "porous medium" separate from the rock matrix and would be discretely defined by special fracture elements in a finite-element mesh. 
Therefore, the basic balance equations are the same for rock matrix and fracture materials, while some of the constitutive relations differ. With this approach and these assumptions, three balance equations - water mass balance, energy conservation and linear momentum balance - and a number of constitutive relations are required for a full description of the THM state. The ROCMAS code includes various versions of constitutive geomechanical models for solid rocks, soils and discrete fractures including (Noorishad and Tsang, 1996):

- Linear elastic solid

- Associated and non-associated strain softening/hardening elastoplastic continuum

- Sandler/DeMaggio cap plasticity

- Oriented plasticity

- Compressible, dilating and strain softening elasto-plastic joints

- No tension continuum

The cap plasticity model may be applied to unconsolidated clay to model pore-collapse in addition to shear failure.

\subsubsection{The TOUGH-FLAC Simulator}

The TOUGH-FLAC was developed as a pragmatic approach for modeling coupled multiphase flow, heat transport and geomechanics, by linking the two established codes TOUGH2 and FLAC $^{3 \mathrm{D}}$ (Rutqvist et al., 2002). In this approach, TOUGH2 (Pruess et al., 1999) is used for solving multiphase flow and heat transport equations, whereas FLAC ${ }^{3 \mathrm{D}}$ (Itasca, 2009) is used for solving geomechanical stress-strain equations. The TOUGH-FLAC simulator was originally developed for analysis of coupled THM processes associated with the Yucca Mountain Project. The FLAC ${ }^{3 \mathrm{D}}$ code was selected for the coupling to TOUGH2, because it is a well-established commercial code that has been extensively tested and verified. The two codes are sequentially coupled, but a TOUGH-FLAC simulation runs seamlessly. A great advantage with the adopted approach is that both codes are continuously developed and widely used in both academia and industry.

The simulator has been applied to study coupled geomechanical aspects under multiphase flow conditions for a wide range of applications, including nuclear waste disposal, $\mathrm{CO}_{2}$ sequestration, geothermal energy extraction, naturally occurring $\mathrm{CO}_{2}$ upwelling with surface deformations, and gas production from hydrate-bearing unconsolidated sediments. These applications have been accompanied with exploratory code developments. The most significant new development is a revised architecture compared to the earlier attempts, enabling a more rigorous and tight coupling procedure with improved computational efficiency. This development occurred when coupling the newly released TOUGH+ code to FLAC3D for the analysis of the geomechanical performance of hydrate-bearing unconsolidated sediments (Rutqvist and Moridis, 2009).

For analysis of coupled THM problems, the TOUGH2 and FLAC ${ }^{3 \mathrm{D}}$ are executed on compatible numerical grids and linked through a coupled THM model (Figure 3-1) with coupling functions serving to pass relevant information between the field equations that are solved in respective code. Depending on the problem and specific porous media (e.g., fractured rock, unsaturated clay, or hydrate-bearing sediments), a number of coupling functions have been developed. 


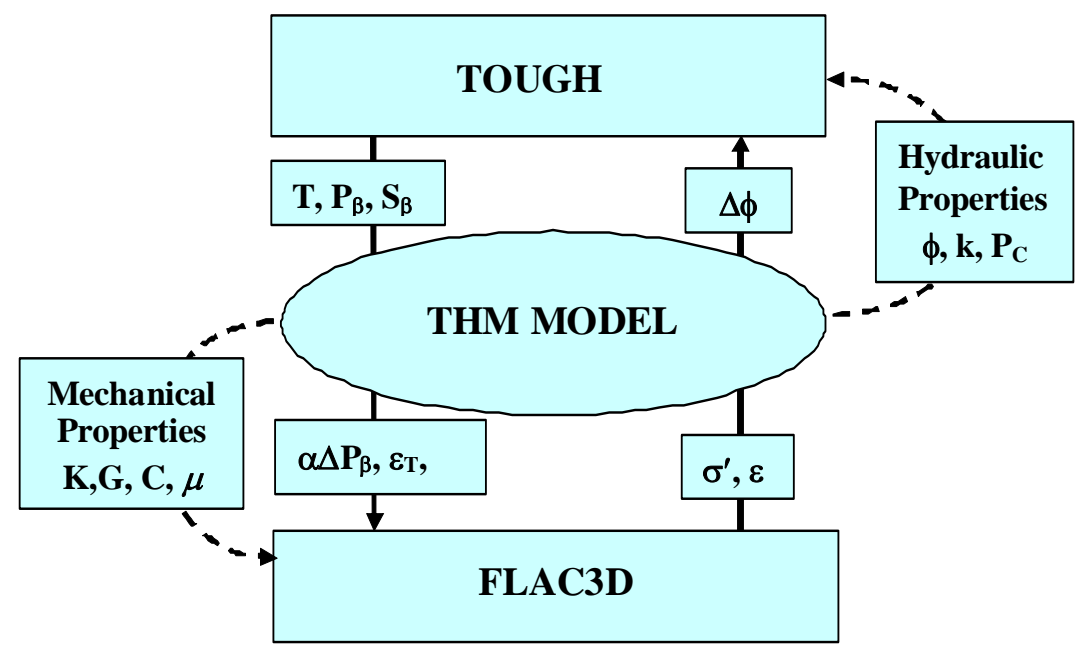

\begin{tabular}{|l|}
\hline -- Direct couplings \\
- - Indirect coupling \\
C = Cohesion \\
$\mathrm{G}=$ Shear modulus \\
$\mathrm{K}=$ Bulk modulus \\
$\mathrm{k}=$ Intrinsic permeability \\
$\mathrm{P}=$ Pressure
\end{tabular}

\begin{tabular}{|l|}
\hline $\mathrm{P}_{\mathrm{C}}=$ Capillary pressure \\
$\mathrm{S}_{\mathrm{H}}=$ Hydrate saturation \\
$\mathrm{T}=$ Temperature \\
$\varepsilon=$ Strain \\
$\phi=$ Porosity \\
$\mu=$ Coefficient of friction \\
$\sigma^{\prime}=$ Effective stress \\
\hline
\end{tabular}

Figure 3-1. Schematic of linking TOUGH family code such as TOUGH+ and TOUGH2 with FLAC ${ }^{3 \mathrm{D}}$ for a coupled THM simulation.

In FLAC $^{3 \mathrm{D}}$, the basic explicit dynamic calculation iterates between solving the equation of motion and the stress-strain constitutive equation using a sufficiently small time step to assure numerical stability. In one time step, the equation of motion is first invoked to calculate new velocities based on previous velocities and forces. The nodal velocities are then used to derive new strain rates and stress, which in turn are used to update the force vector. The final solution is reached (using a damped solution) when the body is in equilibrium or in steady-state flow (plastic flow), and the out of balance force goes to zero.

A large number of constitutive geomechanical models are readily available in FLAC ${ }^{3 \mathrm{D}}$, for both solid and interface elements, including:

- Elastic, isotropic, orthotropic, and transversely anisotropic

- Strain hardening/softening Mohr-Coulomb plasticity

- Ubiquitous joint (anisotropic) strain-hardening/softening bi-linear plasticity

- Double-yield plasticity

- Modified Cam-Clay 
- Various creep models

In Figure 3-1, the data exchanges between TOUGH and FLAC ${ }^{3 \mathrm{D}}$ are illustrated with arrows going through the central THM model. The arrow on the right-hand side of Figure 3-1 shows the transmission of the effective stress $\sigma^{\prime}$ and strain $\varepsilon$ (that are computed in $\mathrm{FLAC}^{3 \mathrm{D}}$ ) to TOUGH for calculation of the updated porosity $\phi$ and the corresponding porosity change $\Delta \phi$. This mechanically induced $\Delta \phi$ has an immediate effect on fluid flow behavior. For example, if a change in $\sigma^{\prime}$ and $\varepsilon$ causes $\phi$ to decrease, the pore pressure is expected to rise, especially if the permeability is low.

For porous deformable media, two models for mechanically induced porosity changes are implemented in the most recent version linking FLAC $^{3 \mathrm{D}}$ to TOUGH+

(i) A poroelastic model (based on the approach proposed by Settari and Mourits (1998) that considers macroscopic stress/strain changes and grain deformability

(ii) An empirical model (proposed by Rutqvist and Tsang, 2002) that describes a nonlinear change in porosity as a function of the effective mean stress

The $\Delta \phi$ computed from either of these models is used to estimate changes in $k$ by means of empirical equations. The updated $\phi$ and $k$ values are in turn used to estimate changes in the hydraulic and wettability properties of the porous medium (i.e., aqueous- and gas-phase relative permeabilities $k_{r A}$ and $k_{r G}$, and capillary pressure $P_{c}$ ) by employing appropriate scaling equations. For fractured media, a similar exponential empirical model has been applied to correct permeability for changes in the stress field (e.g., Rutqvist et al., 2002).

The arrow on the left side of Figure 3-1 depicts the flow of data obtained from TOUGH (namely the pressure $P$, temperature $T$, and phase saturations $S_{\beta}$ ) to $\mathrm{FLAC}^{3 \mathrm{D}}$ for processing and estimation of their impact on the effective stress $\alpha \Delta P_{\beta}$ ( $\alpha$ being Biot's effective stress parameter), as well as on thermal and swelling strains ( $\varepsilon_{T}$ and $\varepsilon_{s w}$, respectively).

Additionally, changes in $P, T$, and $S_{\beta}$ may also result in changes in other mechanical properties listed in Figure 3-1. These include the bulk modulus $K$, the shear modulus $G$, the cohesion $C$, and the coefficient of internal friction $\mu$. For example, in the case of hydrate-bearing sediment, geomechanical properties change as a function of solid-phase saturations, i.e., hydrate and ice saturations ( $S_{H}$ and $S_{I}$, respectively). In the case of unsaturated soil, the bulk modulus and friction angle is a function of suction.

\subsubsection{Comparison of ROCMAS and TOUGH-FLAC to Other THM codes}

A steadily growing interest in coupled THM phenomena in geological media has encouraged development of many computer codes at various levels of sophistication. Among those recently applied in the field of rock mechanics are THAMES (Ohnishi and Kobayashi, 1996), MOTIF (Guvanasen and Chan, 1995), FRACON (Nguyen, 1996), FEHM (Bower and Zyvoloski, 1997), GeoSys/Rockflow, (Kolditz et al. 2003), FRT-THM, (Liu et al. 2006), FRIP (Pine and Cundall, 1985), FRACture (Kohl and Hopkirk, 1995) and GEOCRACK (Swenson et al. 1997). The first four of these have been applied mostly in the field of geological disposal of nuclear waste, while the last three have been applied to the field of hot-dry-rock geothermal energy. There are also a few 
commercially available codes that have been applied to study these phenomena. The most frequently applied in soil and rock mechanics are ABAQUS (Börgesson, 1996), a finite-element code; FLAC (Israelsson, 1996a), a finite-difference code; and UDEC (Israelsson, 1996b), a discrete-element code.

A number of simulators have been developed focusing on oil and gas reservoir engineering, including commercial finite-element packages such as VISAGE (Koutsabeloulis, 1998), GMCSTARS, and a number of academic codes. TOUGH-FLAC is in the class of coupled simulators that is built upon coupling of a reservoir simulator to a geomechanical code. It is a delicate operation to correctly change the porosity of the reservoir simulator upon a change in stress or strain in the mechanical code. The ideas of Settari and Mourits (1998) have been implemented in TOUGH-FLAC coupling as one alternative poro-elastic model. The correct poro-elastic consideration is important when comparing simulation results to that of fully coupled poroelastic finite element models of the Biot type. However, as described by Settari and Mourits (1998), in practice it is more important to consider the nonlinear stress-dependent effects on porosity and permeability over the range of stress expected in a problem. Such properties may be derived directly from laboratory data and fitted to theoretical or empirical functions (e.g., Liu et al., 2009) or by calibration to field experiments (e.g., Rutqvist et al., 2008a).

In summary, it can be concluded that a large number of simulators have been developed for the analysis of coupled THM processes over the past 30 years. The ROCMAS code and TOUGHFLAC are two different types of simulators that complement each other, have been extensively applied, and yet have the flexibilities for modifications and future improvements, such as linkage to TOUGHREACT for fully coupled THMC processes. When evaluating the capabilities of a code it is important to look at how it has been applied. The next section presents on example application of the ROCMAS and TOUGH-FLAC simulators related to nuclear waste isolation.

\subsection{Simulation of a Generic Repository in Clay Host Rock}

This section presents the initial results of the simulation of coupled THM processes in the EBS and host rock for high-level radioactive waste repository in clay formations. It is our intent to investigate the coupled THM behavior for a range of clay host rocks, including plastic clay and indurated more brittle claystone. In our first base case simulation scenario we will use clay host rock properties derived from the Opalinus clay stone at Mont Terri, Switzerland (Table 3-1), and will use a repository design and EBS with emplacement into horizontal tunnels that are backfilled with bentonite-based swelling clays as a protective buffer. We adopt the heat load developed for the Generic Disposal System Environment (GDSE) within the UFD for Pressurized Water Reactor (PWR) used nuclear fuel. The first step in this analysis is to design the repository in terms of spacing between emplacement tunnels and individual waste packages along the tunnels, to achieve a distributed heat load that would meet criteria for desired maximum temperature. 
Table 3-1. Some basic THM rock properties used for simulation of a repository hosted in clay stone.

\begin{tabular}{|l|l|}
\hline \hline Parameter & \\
\hline \hline Bulk Density, $\left[\mathrm{kg} / \mathrm{m}^{3}\right]$ & 2400 \\
\hline Matrix Porosity $[-]$ & 0.15 \\
\hline Young's Modulus, $[\mathrm{GPa}]$ & 5 \\
\hline Poisson's ratio, $[-]$ & 0.3 \\
\hline Specific heat, $\left[\mathrm{J} / \mathrm{kg} \cdot{ }^{\circ} \mathrm{C}\right]$ & 900 \\
\hline Thermal conductivity, $\left[\mathrm{W} / \mathrm{m} \cdot{ }^{\circ} \mathrm{C}\right]$ & 2.2 \\
\hline Thermal expansion coefficient, $\left[{ }^{\circ} \mathrm{C}^{-1}\right]$ & $1.0 \times 10^{-5}$ \\
\hline Permeability, $\left[\mathrm{m}^{2}\right]$ & $5.0 \times 10^{-20}$ \\
\hline Biot's effective stress parameter & 1.0 \\
\hline van Genuchten water retension parameter, $\mathrm{m}$ & 0.41 \\
\hline van Genuchten water retnesion parameter, $\mathrm{P}_{0}[\mathrm{MPa}]$ & 48 \\
\hline
\end{tabular}

\subsubsection{The Repository Design and Heat Load}

We chose a repository design similar to the one considered in Swiss nuclear waste disposal program for a repository in Opalinus Clay. We assume that the drift is located at a depth of 500 $\mathrm{m}$ and the top boundary located at the ground surface. The heat load for individual emplacement tunnels and their spacing are designed by a constraint of a maximum temperature of $100{ }^{\circ} \mathrm{C} \max$ in the contact between the canister and the bentonite. In repository designs with bentonitebackfilled repository tunnels, the PWR type of used fuel is typically packed into a waste package (or canister) with the dimensions of about $1 \mathrm{~m}$ in diameter and about $4 \mathrm{~m}$ long. This is dictated by the length of individual PWR fuel elements and the number of fuel elements per waste package. 4 PWR elements per waste package are commonly adopted for bentonite-backfilled repositories in various host rocks, including crystalline and clay (e.g. Swedish and Finish, Swiss, and Spanish proposed repository designs). Moreover, the emplacement tunnels may be typically up to $1 \mathrm{~km}$ long. The basic material properties used in this initial simulation are presented in Table 3-2. 
Table 3-2. Thermal and hydraulic material parameters for the FEBEX buffer material used in the numerical modeling of swelling experiment and multiple barrier repository.

\begin{tabular}{|l|l|}
\hline \multicolumn{1}{|c|}{ Parameter } & \multicolumn{1}{c|}{ Value/Function } \\
\hline Initial dry density, $\rho_{d}\left[\mathrm{~kg} / \mathrm{m}^{3}\right]$ & $1.6 \cdot 10^{3}$ \\
\hline Initial porosity, $\phi[-]$ & 0.41 \\
\hline Saturated permeability, $k\left[\mathrm{~m}^{2}\right]$ & $2.0 \cdot 10^{-21}$ \\
\hline Relative permeability, $k_{r}[-]$ & $k_{r l}=S_{l}^{3}$ \\
\hline van Genuchten's $(1980)$ parameter, $P_{V G}[\mathrm{MPa}]$ & 30 \\
\hline van Genuchten's $(1980)$ parameter, $\lambda_{V G}[-]$ & 0.32 \\
\hline Thermal expansion, $\beta\left[1 /{ }^{\circ} \mathrm{C}\right]$ & $1.5 \cdot 10^{-4}$ \\
\hline Dry specific heat, $\mathrm{C}_{\mathrm{s}}\left[\mathrm{J} / \mathrm{kg} \cdot{ }^{\circ} \mathrm{C}\right]$ & $c_{s}=1.38 T+732.5$ \\
\hline $\left.\begin{array}{l}\text { Thermal conductivity, } \lambda_{m}\left[\mathrm{~W} / \mathrm{m} \cdot{ }^{\circ} \mathrm{C}\right] \\
\hline \begin{array}{l}\text { Effective molecular diffusion coefficient, } D_{v} \\
{\left[\mathrm{~m}^{2} / \mathrm{s}\right]}\end{array}\end{array}\right) \lambda_{m}=2.16 e-5 \times \tau \times \phi \times S_{g}\left(\frac{T_{a b s}}{273.8}\right)^{1.8}$ \\
\hline Tortuousity, $\tau[-]$ & 0.8 \\
\hline
\end{tabular}

The thermal decay curves for a 10 PWR element waste package was scaled down by multiplying by $4 / 10$ to obtain the decay curve for a 4 PWR element waste package that would match the adopted repository design. This leads to an initial thermal power of $3144 \mathrm{~W}$ per waste package. Assuming a waste deposition after 60 years of interim storage, the heat power has decayed to 1818 Watts per waste package. With the assumption of the $50 \mathrm{~m}$ tunnel spacing and $500 \mathrm{~m}$ emplacement depth, the average thermal power per meter drift may be scaled by adjusting the spacing between individual waste packages along the tunnel. Using model calibration and a maximum temperature kept below $100^{\circ} \mathrm{C}$, we adopted an average thermal power of $200 \mathrm{~W}$ per meter drift. This would mean that if the individual waste packages are $4 \mathrm{~m}$ long, the spacing would be $4 \mathrm{~m}$. Alternatively, for $3 \mathrm{PWR}$ elements per waste package the spacing would be $2 \mathrm{~m}$. For the adopted average thermal conductivity of the rock $\left(2.2 \mathrm{~W} / \mathrm{m}^{\circ} \mathrm{C}\right)$, an average thermal power of $200 \mathrm{~W}$ per meter drift seems to be the upper practical limit for this type of repository design. Figure 3-2 presents the model dimensions and the heat decay curve for these simulations. 


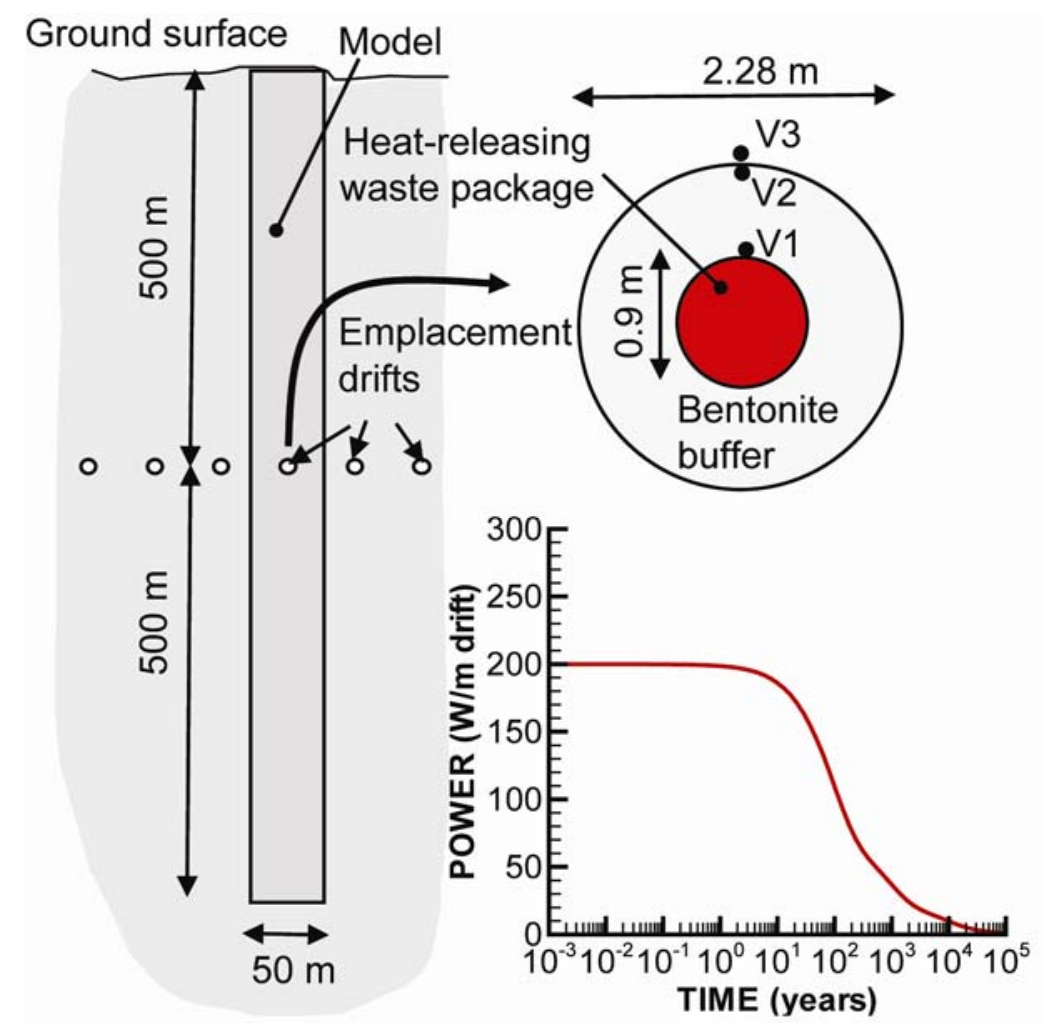

Figure 3-2. Model domain for a repository hosted in clay stone.

\subsubsection{Modeling Sequence, Boundary and Initial Conditions}

Figure 3-3 presents the detailed modeling sequence, boundary and initial conditions for the coupled THM simulation. The initial conditions for the rock mass are established at the preexcavation stage (Figure 3-3(1)). The initial stress was defined as $\sigma_{\mathrm{h}}=\sigma_{\mathrm{H}}=\sigma_{\mathrm{v}}=2400 \cdot 9.81 \cdot \mathrm{D}$ where $\mathrm{D}$ is elevation relative to ground surface $(\mathrm{D}=\mathrm{z}-500$ and tensile stress is positive). The vertical thermal gradient is assumed to be $30^{\circ} \mathrm{C} / \mathrm{km}$ with a fixed average temperature of $10^{\circ} \mathrm{C}$ on the ground surface and a fixed temperature of $40{ }^{\circ} \mathrm{C}$ at the bottom boundary. The groundwater table is assumed to be located at the ground surface where the pressure is fixed to $0.1 \mathrm{MPa}$ (atmospheric). At the bottom of the model the fluid pressure is set to $9 \mathrm{MPa}$, which slightly less than hydrostatic. The excavation sequence can be simulated in a one-step steady state calculation with the elements in the drift removed and constant temperature $25^{\circ} \mathrm{C}$ and pressure of $0.1 \mathrm{MPa}$ at the drift boundary (Figure 3-3(2)). After the steady state excavation simulation is completed, the waste canister, bentonite buffer and back-fill are installed instantaneously and the post-closure simulation can start (Figure 3-3(3) and 3-3(4)). 


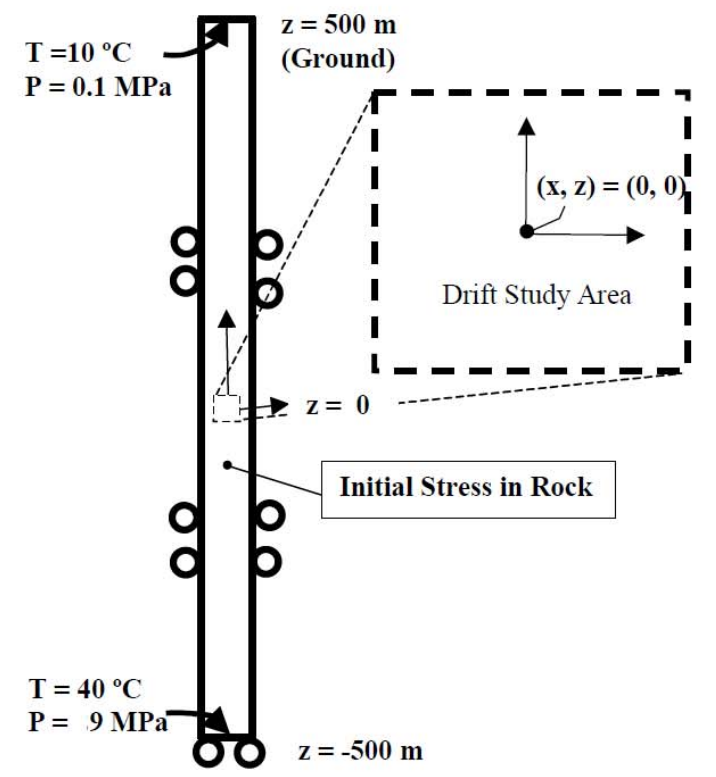

1) Pre-excavation Conditions

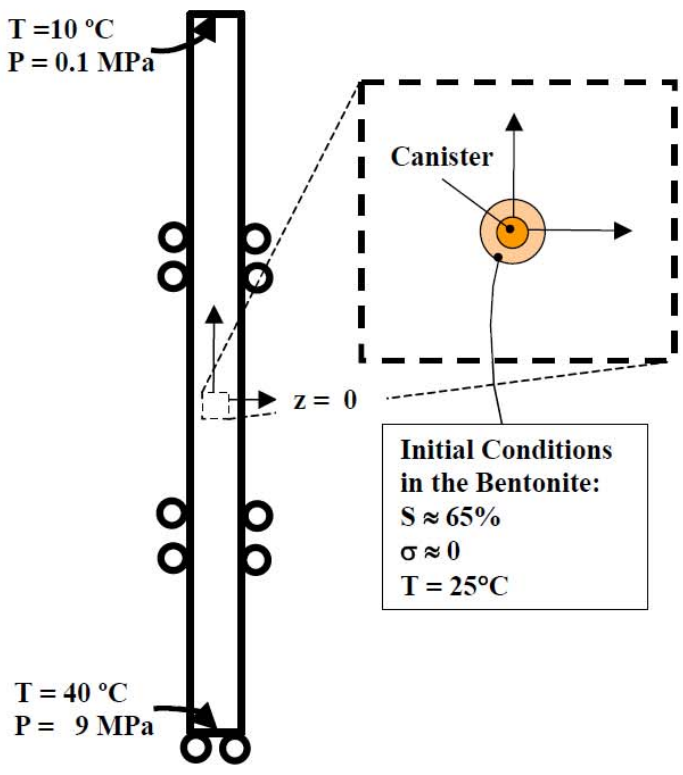

3) Installation of Bentonite Buffer

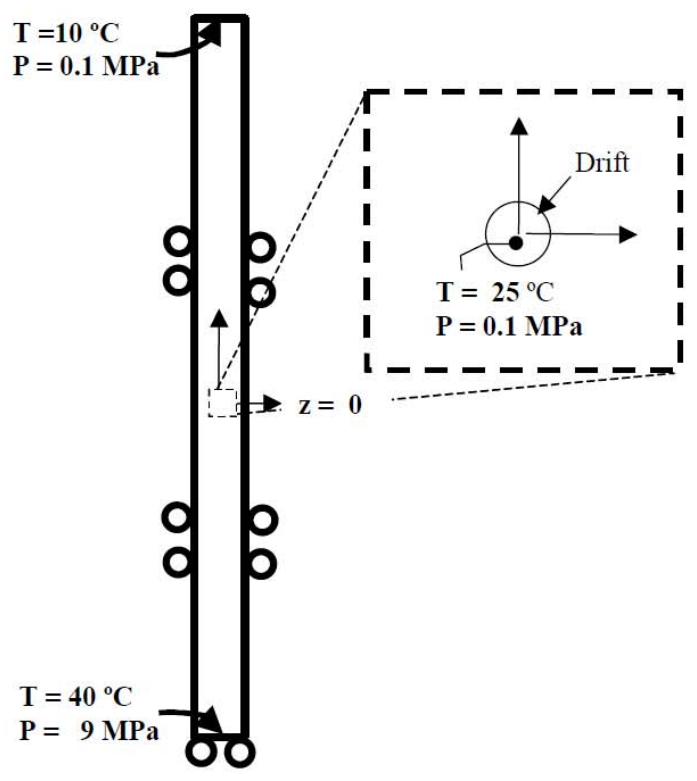

2) Steady State Simulation of Excavation

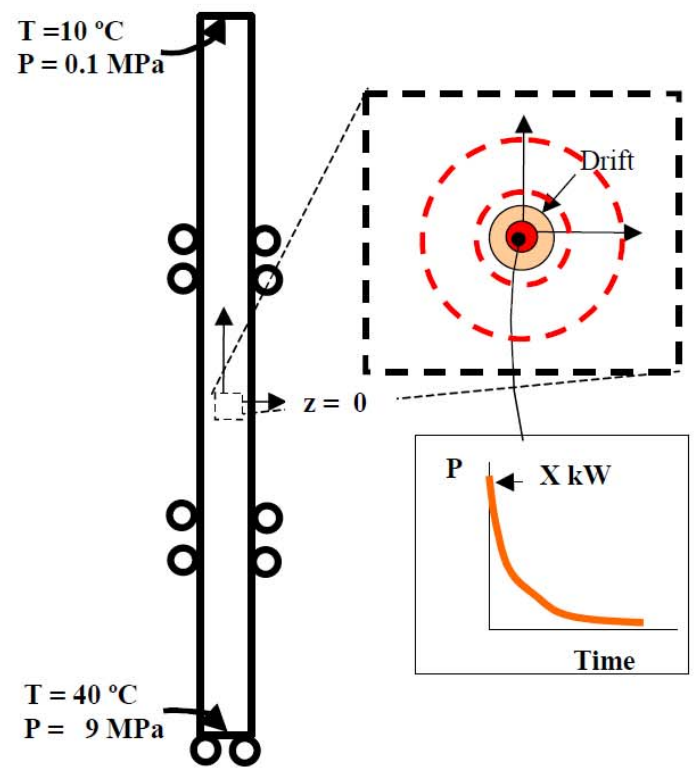

4) Transient Simulation of Post-closure THM

Figure 3-3. Modeling sequence, boundary and initial conditions. 


\subsubsection{Basic THM simulation results}

Figure 3-4 presents the calculated evolution of temperature, saturation, fluid pressure, and stress within the buffer. The temperature peaks at about $95^{\circ} \mathrm{C}$, which is below the $100^{\circ} \mathrm{C}$ maximum temperature criterion. The resaturation of the buffer is delayed as a result of the low rock permeability and a slight desaturation of the rock can be observed in Figure 3-4b. The fluid pressure indicates a strong coupling to the temperature field, and as a result of the low rock permeability a significant thermal pressurization occurs (Figure 3-4c). This increase in fluid pressure has a direct impact on the stress evolution in the buffer (Figure 3-4d). Thus, in this case we observe strong interaction between the host rock coupled processes and the THM evolution of the buffer. The results presented are valid for an average permeability representative of 5e-20 $\mathrm{m}^{2}$. If the permeability is lower, a much stronger thermal pressurization can occur.

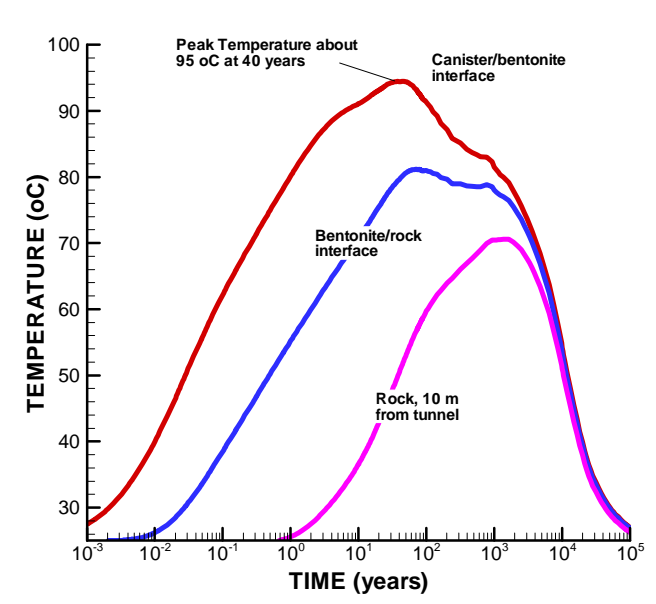

(a)

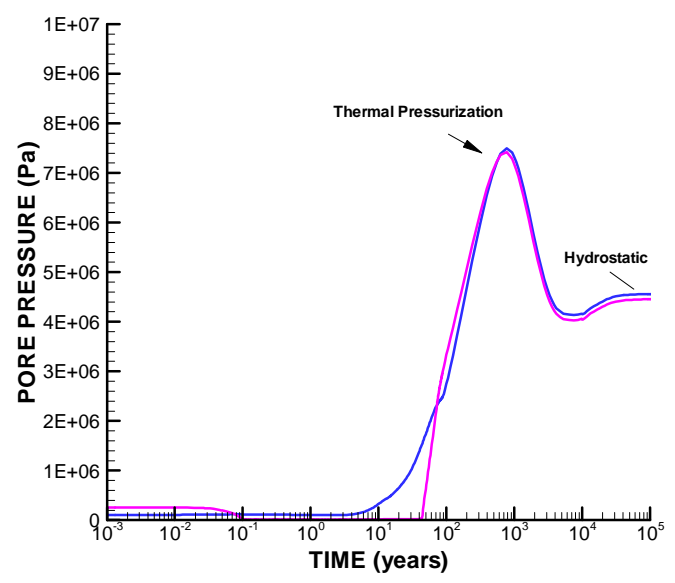

(c)

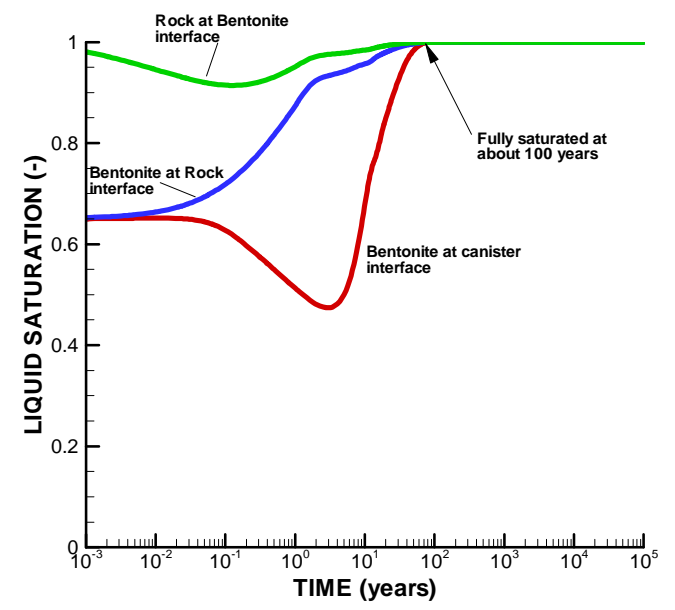

(b)

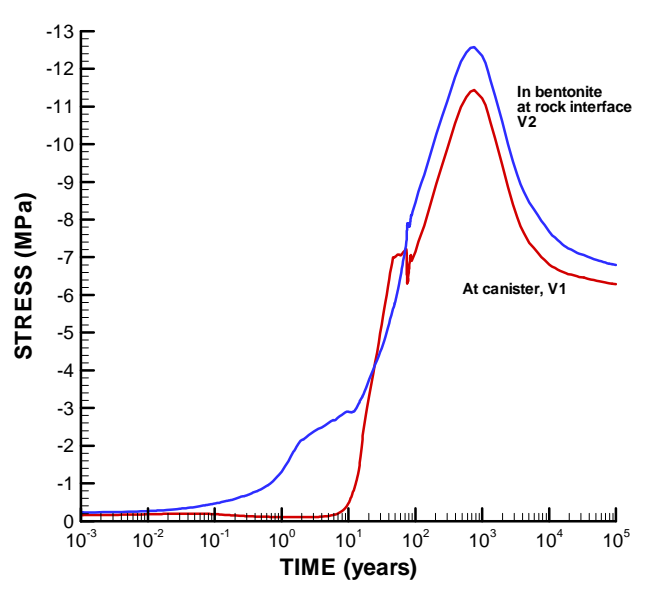

(d)

Figure 3-4. Simulated evolution of THM processes in the buffer: (a) temperature at V1, V3, and V6 (b) liquid saturation at V1, (c) fluid pressure at V3, and (d) total radial stress $\left(\sigma_{x}\right)$ at $\mathrm{V} 1$ and $\mathrm{V} 2$. See Figure 3-2 for definitions of V1, V2, and V3. 


\subsubsection{Summary of THM Research for Clay/Shale Environments and Next Step}

We have conducted initial simulation studies of coupled THM processes in the EBS and host rock for high-level radioactive waste repository in clay formations. This study highlights the important interactions between the buffer and the host rock, in particular regarding the potential for desaturation of the rock and thermal pressurization which can have a significant impact of the coupled THM evolution.

Future work is proposed to include modeling that addresses fracture growth, self-sealing and self-healing behavior. This will involve new constitutive models such as discussed in Section 2 and calibration and confirmation using experimental data.

\section{THC MODELING IN CLAY/SHALE ENVIRONMENTS}

In this section, a summary of the TOUGHREACT code is presented followed by modeling results for THC studies in a clay host rock.

\subsection{TOUGHREACT Code}

Coupled modeling of subsurface multiphase fluid and heat flow, solute transport, and chemical reactions can be applied to many geologic systems and environmental problems, including geothermal systems, diagenetic and weathering processes, nuclear waste emplacement, acid mine drainage remediation, contaminant transport, and groundwater quality. TOUGHREACT has been developed as a comprehensive non-isothermal multi-component reactive fluid flow and geochemical transport simulator to investigate these and other problems (Xu et al., 2008). A number of subsurface thermo-physical-chemical processes are considered under various thermohydrological and geochemical conditions of pressure, temperature, water saturation, and ionic strength. TOUGHREACT can be applied to one-, two- or three-dimensional porous and fractured media with physical and chemical heterogeneity. The code can accommodate any number of chemical species present in liquid, gas and solid phases. A variety of equilibrium chemical reactions are considered, such as aqueous complexation, gas dissolution/exsolution, and cation exchange. Mineral dissolution/precipitation can take place subject to either local equilibrium or kinetic controls, with coupling to changes in porosity and permeability and capillary pressure in unsaturated systems. Chemical components can also be treated by linear adsorption and radioactive decay.

The first version of the non-isothermal reactive geochemical transport code TOUGHREACT was developed (Xu and Pruess, 1998) by introducing reactive geochemistry into the framework of the existing multi-phase fluid and heat flow code TOUGH2 (Pruess, 1991). TOUGHREACT was further enhanced with the addition of (1) treatment of mineral-water-gas reactive-transport under boiling conditions, (2) an improved HKF activity model for aqueous species, (3) gas species diffusion coefficients calculated as a function of pressure, temperature, and molecular properties, (4) mineral reactive surface area formulations for fractured and porous media, and (5) porosity, permeability, and capillary pressure changes owing to mineral precipitation/dissolution. Subsequently, TOUGH2 V2 was released with additional EOS modules and features (Pruess et al., 1999 which was incorporated into the present version of TOUGHREACT (Xu et al., 2006). 


\subsubsection{Major Processes Treated by TOUGHREACT}

The major processes for fluid and heat flow are: (1) fluid flow in both liquid and gas phases occurs under pressure, viscous, and gravity forces; (2) interactions between flowing phases are represented by characteristic curves (relative permeability and capillary pressure); (3) heat flow by conduction and convection, and (4) diffusion of water vapor and air. Thermophysical and geochemical properties are calculated as a function of temperature, such as fluid (gas and liquid) density and viscosity, and thermodynamic and kinetic data for mineral-water-gas reactions. Transport of aqueous and gaseous species by advection and molecular diffusion are considered in both liquid and gas phases. Depending on the computer memory and CPU performance, any number of chemical species in the liquid, gas and solid phases can be accommodated. Aqueous complexation, acid-base, redox, gas dissolution/exsolution, and cation exchange are considered under the local equilibrium assumption. Mineral dissolution and precipitation can proceed either subject to local equilibrium or kinetic conditions. Linear adsorption and decay can be included.

\subsubsection{Governing Equations}

The primary governing equations for multiphase fluid and heat flow, and chemical transport have the same structure, derived from the principle of mass (or energy) conservation. These equations, implemented in TOUGHREACT, are presented in Xu et al. (2008). Expressions for nonisothermal multiphase flow are given in Pruess (1987) and Pruess et al. (1999). The transport equations are written in terms of total dissolved concentrations of chemical components, which are concentrations of the basis species plus their associated aqueous secondary species (Yeh and Tripathi, 1991; Steefel and Lasaga, 1994; Walter and others, 1994; Lichtner, 1996; and Xu and Pruess, 2001). If kinetically-controlled reactions occur between aqueous species, then additional ordinary differential equations need to be solved to link the total concentrations of the primary species with the evolving concentrations of the secondary species (Steefel and MacQuarrie, 1996). Kinetically-controlled reactions between aqueous species are not considered in the present version of TOUGHREACT. Slow aqueous phase reactions are common in the case of redox reactions and will be addressed in future development. Advection and diffusion processes are considered for both the aqueous and gaseous species. Aqueous species diffusion coefficients are assumed to be the same. Gaseous species, having a neutral valence, can have differing diffusion coefficients calculated as a function of T, P, molecular weight, and molecular diameter. The local chemical interactions in the transport equations are represented by reaction source/sink terms.

The primary governing equations must be complemented with constitutive local relationships that express all parameters as functions of fundamental thermophysical and chemical variables. The equations for chemical reactions are presented in Xu et al., (2008). Mass conservation in the closed chemical system is written in terms of basis (component) species. The species distribution must be governed by the total concentrations of the components. The oxygen is used for formulating redox reactions by attributing the oxidizing potential to the dissolved oxygen (Nordstrom and Muñoz, 1986; Wolery, 1992). In contrast to the free electron in the hypothetical electron approach (Yeh and Tripathi, 1991), oxygen can be present and can be transported in natural subsurface flow systems. The formulation for cation exchange is similar to that of Appelo and Postma (1993). For kinetically-controlled mineral dissolution and precipitation, a general 
form of rate law (Lasaga, 1984; Steefel and Lasaga, 1994; Palandri and Kharaka, 2004) is used (Xu et al., 2008). Thermodynamic and kinetic data are functions of temperature.

Temporal changes in porosity, permeability, and unsaturated hydrologic properties owing to mineral dissolution and precipitation can modify fluid flow. This feedback between transport and chemistry can be important (e.g., Raffensperger, 1996; Dobson et al., 2003), and can be treated by TOUGHREACT. Changes in porosity during the simulation are calculated from changes in mineral volume fractions. The porosity-permeability correlation in geologic media can be complex, depending on several factors, such as pore size distribution, pore shapes, connectivity (Verma and Pruess, 1988), and crystal morphology. Several porosity-permeability and fracture aperture-permeability relationships are included in the model (Xu et al., 2008). The code can also be set to monitor changes in porosity and permeability during the simulation without considering their effects on fluid flow. In unsaturated systems, capillary pressure can be modified via permeability and porosity changes using Leverett scaling (based on Slider, 1976).

\subsection{Application of TOUGHREACT to Bentonite-Filled EBS and Clay Formation}

This simulation problem deals with water-rock interactions around nuclear waste packages emplaced in clay formation with bentonite backfill. The model setup is similar to the benchmark for the DECOVALEX-THMC project (Sonnenthal, 2008). The grid for the simulations is shown in Figure 4-1. Because the model was intended for demonstration of the code capability of simulating the THC behavior in the EBS and clay formation, it was set up in a very simplified manner (e.g., only aqueous complexation and mineral dissolution/precipitation are considered). Therefore, this problem should not be taken as an accurate representation of a nuclear waste repository. Nevertheless, this problem illustrates typical coupled thermal-hydrological-chemical processes that could occur in the EBS and clayey host rock around nuclear waste packages as influenced by the very different near-field mineralogy and water chemistry. Details of model setup and results are given in the following sections.

\subsubsection{Model Setup}

The model assumes that initially both clay formation and bentonite EBS are fully saturated. The top boundary $(+500 \mathrm{~m})$ has a fixed temperature of $10{ }^{\circ} \mathrm{C}$ and pressure of $0.1 \mathrm{MPa}$. The bottom boundary $(-500 \mathrm{~m})$ has also fixed temperature and pressure of $40{ }^{\circ} \mathrm{C}$ and $0.9 \mathrm{MPa}$ respectively. The fixed pressures on the top and bottom boundary yield a downward flow around $3 \mathrm{~mm} /$ year. The heat input from the inner boundary is the same as that used for the THM model (see Section $3)$. 


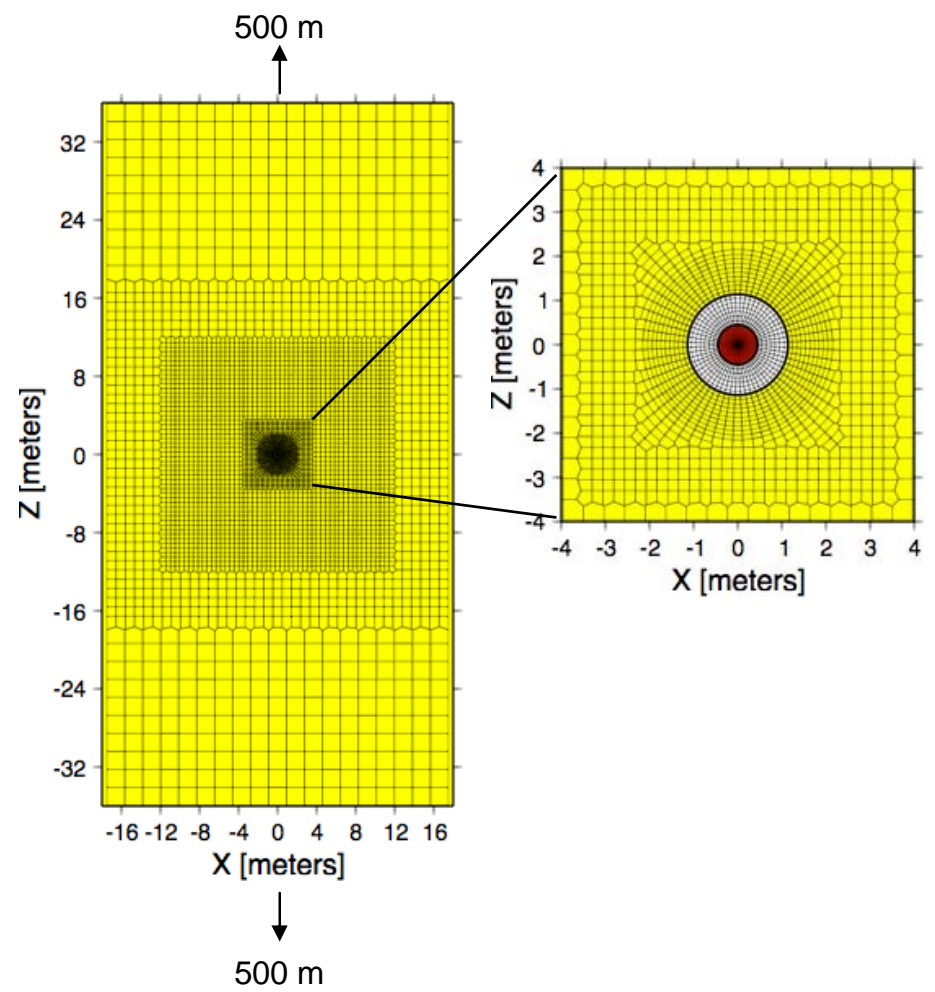

Figure 4-1. Two-dimensional numerical integral finite difference unstructured mesh for TOUGHREACT simulations (left) and enlargement of drift mesh (right) showing waste canister (red), bentonite buffer (white), and drift wall boundary. Mesh extends $500 \mathrm{~m}$ above and below the drift center, and $17.5 \mathrm{~m}$ to each side.

The mineralogical composition of bentonite (Table 4-1) is taken from the Kunigel-V1 bentonite (Ochs et al., 2004). The clay formation is assumed to be Opalinus Clay investigated in the Mont Terri underground rock laboratory in Switzerland (Thury, 2002) and the mineral composition is given in Table 4-2.

Table 4-1. Mineral composition of the bentonite used in the model (taken from the Kunigel-V1 bentonite (Ochs et al., 2004)).

\begin{tabular}{|c|c|}
\hline Mineral & Abundance (volume fraction) \\
\hline Na-montmorillonite & 0.475 \\
\hline Quartz & 0.335 \\
\hline K-Feldspar & 0.041 \\
\hline Calcite & 0.0235 \\
\hline Dolomite & 0.029 \\
\hline pyrite & 0.006 \\
\hline
\end{tabular}


Table 4-2. Mineral composition of the clay formation used in the model (taken from the Opalinus Clay (Thury, 2002)).

\begin{tabular}{|c|c|}
\hline Mineral & Abundance (volume fraction) \\
\hline Calcite & 0.1 \\
\hline Illite & 0.223 \\
\hline Kaolinite & 0.174 \\
\hline Chlorite & 0.1445 \\
\hline Smectite-na & 0.1426 \\
\hline Quartz & 0.1845 \\
\hline Siderite & 0.01256 \\
\hline Ankerite & 0.00798 \\
\hline Pyrite & 0.01 \\
\hline
\end{tabular}

The pore water composition of the bentonite (Ochs et al., 2004) and clay formation (Fernandez et al., 2007) are listed in Table 4-3. To establish a starting point for the reactive transport model, the initial pore waters are equilibrated with minerals listed in Table 4-1 and 4-2 and the equilibrated waters are listed in the last two column of Table 4-3.

Table 4-3. Initial pore water composition of bentonite and clay formation and the equilibrated water with minerals listed in Table 4-1 and 4-2 respectively (compositions in molal).

\begin{tabular}{|c|c|c|c|c|}
\hline & \multicolumn{2}{|c|}{ Initial } & \multicolumn{2}{c|}{ Equilibrated } \\
\hline & $\begin{array}{c}\text { Bentonite } \\
\text { (Ochs et al., 2004) }\end{array}$ & $\begin{array}{c}\text { Clay formation } \\
\text { (Fernandez et al., 2007) }\end{array}$ & Bentonite & Clay formation \\
\hline $\mathrm{pH}$ & 8.40 & 7.60 & 6.98 & 6.50 \\
\hline $\mathrm{Eh}$ & -0.23 & -0.27 & -0.18 & -0.12 \\
\hline $\mathrm{Cl}$ & $1.50 \mathrm{E}-05$ & $3.32 \mathrm{E}-01$ & $1.50 \mathrm{E}-05$ & $3.32 \mathrm{E}-01$ \\
\hline $\mathrm{SO}_{4}^{-2}$ & $1.10 \mathrm{E}-04$ & $1.86 \mathrm{E}-02$ & $1.21 \mathrm{E}-04$ & $1.86 \mathrm{E}-02$ \\
\hline $\mathrm{HCO}_{3}^{-}$ & $3.50 \mathrm{E}-03$ & $5.20 \mathrm{E}-03$ & $5.21 \mathrm{E}-03$ & $1.26 \mathrm{E}-03$ \\
\hline $\mathrm{Ca}^{+2}$ & $1.10 \mathrm{E}-04$ & $2.26 \mathrm{E}-02$ & $2.77 \mathrm{E}-03$ & $1.50 \mathrm{E}-01$ \\
\hline $\mathrm{Mg}^{+2}$ & $5.50 \mathrm{E}-05$ & $2.09 \mathrm{E}-02$ & $1.82 \mathrm{E}-04$ & $5.59 \mathrm{E}-04$ \\
\hline $\mathrm{Na}^{+}$ & $3.60 \mathrm{E}-03$ & $2.76 \mathrm{E}-01$ & $4.80 \mathrm{E}-03$ & $5.80 \mathrm{E}-02$ \\
\hline $\mathrm{K}^{+}$ & $6.20 \mathrm{E}-05$ & $2.16 \mathrm{E}-03$ & $1.05 \mathrm{E}-04$ & $3.46 \mathrm{E}-06$ \\
\hline $\mathrm{Fe}^{+2}$ & $1.00 \mathrm{E}-10$ & $2.96 \mathrm{E}-07$ & $5.65 \mathrm{E}-06$ & $1.44 \mathrm{E}-03$ \\
\hline $\mathrm{SiO}_{2}(\mathrm{aq})$ & $3.40 \mathrm{E}-04$ & $1.16 \mathrm{E}-04$ & $1.78 \mathrm{E}-04$ & $1.80 \mathrm{E}-04$ \\
\hline $\mathrm{AlO}_{2}^{-}$ & $3.54 \mathrm{E}-08$ & $3.89 \mathrm{E}-06$ & $2.98 \mathrm{E}-08$ & $6.55 \mathrm{E}-10$ \\
\hline
\end{tabular}

Table 4-4 lists the thermal and hydrodynamic parameters used in the model. Those for bentonite are taken from Sonnenthal (2008) while those for clay formation mostly are taken from Thury (2002), except thermal conductivity which is the same as used in the THM model. 
Table 4-4. Thermal and hydrodynamic parameters.

\begin{tabular}{|l|l|l|}
\hline parameter & Clay formation & Bentonite \\
\hline Grain density $\left[\mathrm{kg} / \mathrm{m}^{3}\right]$ & 2700 & 2700 \\
\hline Porosity & 0.15 & 0.41 \\
\hline Saturated permeability $\left[\mathrm{m}^{2}\right]$ & $1.0 \times 10^{-20}$ & $2.0 \times 10^{-21}$ \\
\hline Relative permeability, $\mathrm{k}_{\mathrm{rl}}$ & $m=0.6, \mathrm{~S}_{\mathrm{rl}}=0.01$ & $\mathrm{~K}_{\mathrm{rl}}=\mathrm{S}^{3}$ \\
\hline van Genuchten $\alpha[1 / \mathrm{Pa}]$ & $6.8 \times 10^{-7}$ & $3.3 \times 10^{-8}$ \\
\hline van Genuchten $m$ & 0.6 & 0.3 \\
\hline Compressibility, $\beta[1 / \mathrm{Pa}]$ & $3.2 \times 10^{-9}$ & $5.0 \times 10-8$ \\
\hline $\begin{array}{l}\text { Thermal expansion coeff., } \\
{\left[1 /{ }^{\circ} \mathrm{C}\right]}\end{array}$ & 0.0 & $1.0 \times 10^{-4}$ \\
\hline Dry specific heat, $\left[\mathrm{J} / \mathrm{kg}{ }^{\circ} \mathrm{C}\right]$ & 800 & 8000 \\
\hline $\begin{array}{l}\text { Thermal conductivity }[\mathrm{W} / \mathrm{m} \\
\left.{ }^{\circ} \mathrm{C}\right] \text { dry/wet }\end{array}$ & $2.2 / 2.2$ & $0.5 / 1.3$ \\
\hline Tortuosity & 1.0 & 0.8 \\
\hline
\end{tabular}

Mineral dissolution/precipitation are kinetically controlled, except calcite is assumed in equilibrium. TOUGHREACT (Xu et al., 2006) uses a general form of rate expression, which is based on transition state theory (TST) (Lasaga et al., 1994; Steefel and Lasaga, 1994):

$$
r=k A\left[1-(Q / K)^{\theta}\right]^{\eta}
$$

where $r$ is the kinetic rate (positive values indicate dissolution, and negative values precipitation), $k$ is the rate constant (moles per unit mineral surface area and unit time) which is temperature dependent, $A$ is the specific reactive surface area per $\mathrm{kg} \mathrm{H}_{2} \mathrm{O}, K$ is the equilibrium constant for the mineral-water reaction written for the destruction of one mole of mineral, and $Q$ is the reaction quotient. The parameters $\theta$ and $\eta$ should be determined by experiments, but are commonly set equal to unity when experimental quantification is unavailable. The kinetic rate constants can usually be summed from three mechanisms (Lasaga et al., 1994):

$$
\begin{aligned}
k= & k_{25}^{n u} \exp \left[\frac{-E_{a}^{n u}}{R}\left(\frac{1}{T}-\frac{1}{198.15}\right)\right]+k_{25}^{H} \exp \left[\frac{-E_{a}^{H}}{R}\left(\frac{1}{T}-\frac{1}{198.15}\right)\right] \alpha_{H}^{n_{H}} \\
& +k_{25}^{O H} \exp \left[\frac{-E_{a}^{O H}}{R}\left(\frac{1}{T}-\frac{1}{198.15}\right)\right] \alpha_{H}^{n_{O H}}
\end{aligned}
$$

where subscripts $n u, H$ and $O H$ indicate neutral, acid, and base mechanisms, respectively, $E$ is the activation energy, $k_{25}$ is the rate constant at $25{ }^{\circ} \mathrm{C}, R$ is gas constant, $T$ is the absolute temperature, $a$ is the activity of the species, and $n$ is a power term (constant).

The kinetic law for mineral dissolution/precipitation is given in $\mathrm{Xu}$ et al. (2006). The kinetic rate for the mineral considered in current model is given in Table 4-5. Note that the surface areas 
listed in Table 4-5 are calculated for tuff (Sonnenthal et al., 2005). Their applicability to the clay formation considered are questionable. Further refinement of the surface area calculation is needed in the future when the THC model is applied to a realistic scenario.

Table 4-5. Kinetic properties for minerals considered in the model (Xu et al., 2006)

\begin{tabular}{|c|c|c|c|c|c|c|c|c|c|}
\hline \multirow[t]{3}{*}{ Mineral } & \multirow{3}{*}{$\begin{array}{l}\text { A } \\
\left(\mathrm{cm}^{2} / \mathrm{g}\right)\end{array}$} & \multicolumn{8}{|c|}{ Parameters for Kinetic Rate Law } \\
\hline & & \multicolumn{2}{|c|}{ Neutral Mechanism } & \multicolumn{3}{|c|}{ Acid Mechanism } & \multicolumn{3}{|c|}{ Base Mechanism } \\
\hline & & $\begin{array}{l}\mathbf{k}_{25} \\
\left(\mathrm{~mol} / \mathrm{m}^{2} / \mathrm{s}\right)\end{array}$ & $\begin{array}{l}E_{a} \\
(\mathrm{KJ} / \\
\mathrm{mol})\end{array}$ & $\begin{array}{l}\mathbf{k}_{25} \\
\left(\mathrm{~mol} / \mathrm{m}^{2} / \mathrm{s}\right)\end{array}$ & $\begin{array}{l}E_{a} \\
(\mathrm{KJ} / \\
\mathrm{mol})\end{array}$ & $\mathbf{n}\left(\mathbf{H}^{+}\right)$ & $\begin{array}{l}\mathbf{k}_{25} \\
\left(\mathrm{~mol} / \mathrm{m}^{2} / \mathrm{s}\right)\end{array}$ & $\begin{array}{l}E_{a} \\
(\mathrm{KJ} / \\
\mathrm{mol})\end{array}$ & $\mathbf{n}\left(\mathbf{H}^{+}\right)$ \\
\hline \multicolumn{10}{|l|}{ Primary: } \\
\hline Calcite & \multicolumn{9}{|c|}{ Assumed at equilibrium } \\
\hline Quartz & 9.8 & $1.023 \times 10^{-14}$ & 87.7 & & & & & & \\
\hline K-feldspar & 9.8 & $3.89 \times 10^{-13}$ & 38 & $8.71 \times 10^{-11}$ & 51.7 & 0.5 & $6.31 \times 10^{-12}$ & 94.1 & -0.823 \\
\hline Kaolinite & $1.95 \times 10^{5}$ & $6.91 \times 10^{-14}$ & 22.2 & $4.89 \times 10^{-12}$ & 65.9 & 0.777 & $8.91 \times 10^{-18}$ & 17.9 & -0.472 \\
\hline Smectite-Ca & $5.64 \times 10^{5}$ & $1.66 \times 10^{-13}$ & 35 & $1.05 \times 10^{-11}$ & 23.6 & 0.34 & $3.02 \times 10^{-17}$ & 58.9 & -0.4 \\
\hline Illite & $6.68 \times 10^{5}$ & $1.66 \times 10^{-13}$ & 35 & $1.05 \times 10^{-11}$ & 23.6 & 0.34 & $3.02 \times 10^{-17}$ & 58.9 & -0.4 \\
\hline Chlorite & 9.8 & $3.02 \times 10^{-13}$ & 88 & $7.76 \times 10^{-12}$ & 88 & 0.5 & & & \\
\hline Pyrite & 12.9 & $2.52 \times 10^{-12}$ & 62.76 & $2.34 \times 10^{-7}$ & 43.54 & 1 & & & \\
\hline Dolomite & 12.9 & $2.52 \times 10^{-12}$ & 62.76 & $2.34 \times 10^{-7}$ & 43.54 & 1 & & & \\
\hline Ankerite & 9.8 & $1.26 \times 10^{-9}$ & 62.76 & $6.46 \times 10^{-4}$ & 36.1 & 0.5 & & & \\
\hline Smectite-Na & $5.64 \times 10^{5}$ & $1.66 \times 10^{-13}$ & 35 & $1.05 \times 10^{-11}$ & 23.6 & 0.34 & $3.02 \times 10^{-17}$ & 58.9 & -0.4 \\
\hline Na-montmorillonite & $5.64 \times 10^{5}$ & $1.66 \times 10^{-13}$ & 35 & $1.05 \times 10^{-11}$ & 23.6 & 0.34 & $3.02 \times 10^{-17}$ & 58.9 & -0.4 \\
\hline
\end{tabular}

\subsubsection{Model Results}

In this problem, the heat load results in temperature at the canister-bentonite interface climbing to a maximum near $98{ }^{\circ} \mathrm{C}$ after about 70 years, then slowly dropping back to about $93{ }^{\circ} \mathrm{C}$ after 1000 years. At the bentonite-clay formation interface, temperature increases sharply at the first 100 years and then is stabilized at around $88^{\circ} \mathrm{C}$ after a slow increase up to 700 years.

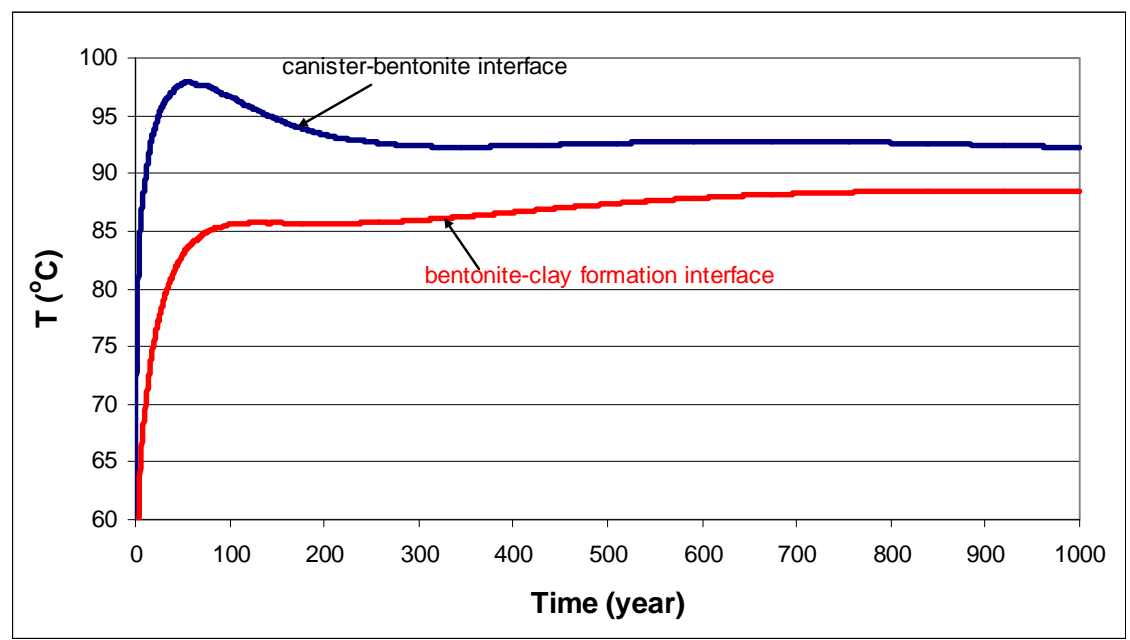

Figure 4-2. Time evolution of temperature at the canister-bentonite interface and bentonite-clay formation interface, respectively. 
Because the simulation starts with saturated condition, some processes which would occur during the hydration of unsaturated bentonite are not counted here (e.g., see Section 2). Diffusion is the only process that controls the transport of conservative species, such as the chloride shown in Figure 4-3. Note that chloride is not necessarily a conservative species, but in current simulations, no chemical reactions will affect the concentration of chloride and therefore chloride is used as representative conservative species here. The diffusive mass transfer between bentonite and clay formation and the change of temperature lead to mineral alteration in bentonite and clay formation, especially near the interface.

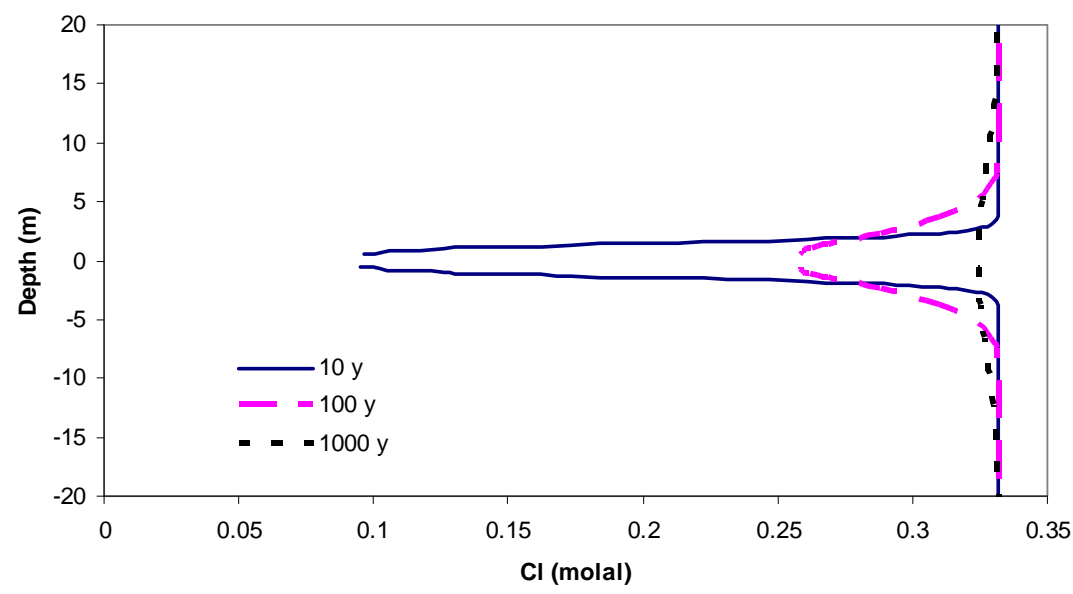

Figure 4-3. Profiles of chloride concentration along $z$ direction at $x=0$ at different times.

Figure 4-4 shows the time evolution of minerals at a point inside the bentonite. Inside the bentonite, minerals alteration is characterized by the dissolution of calcite, K-feldspar and Namontmorillonite and precipitation of quartz, illite and dolomite. Figure 4-5 shows the time evolution of minerals near the bentonite-clay formation interface but on the side of bentonite. Dissolution of dolomite, K-feldspar and Na-montmorillonite and precipitation of calcite, quartz, illite and chlorite are observed. Figure 4-6 shows the change of porosity at the two locations mentioned above. Near the canister, the porosity decreases slightly whereas near the interface, porosity increases about $2 \%$. 


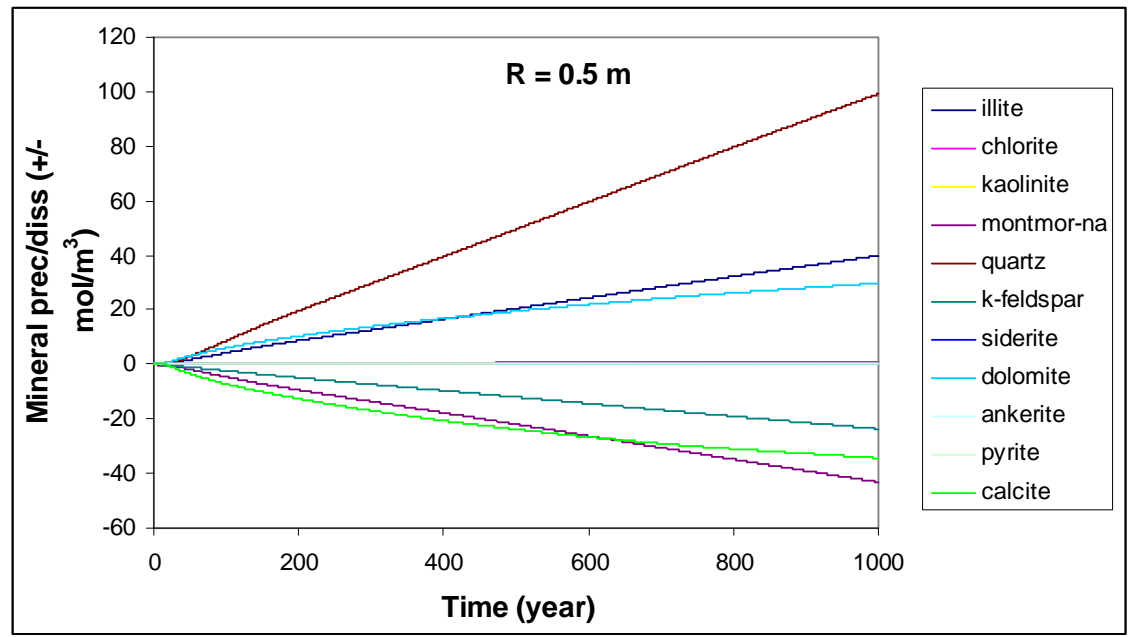

Figure 4-4. Time evolution of mineral dissolution/precipitation at the point inside the bentonite with a radial distance of $0.5 \mathrm{~m}$.

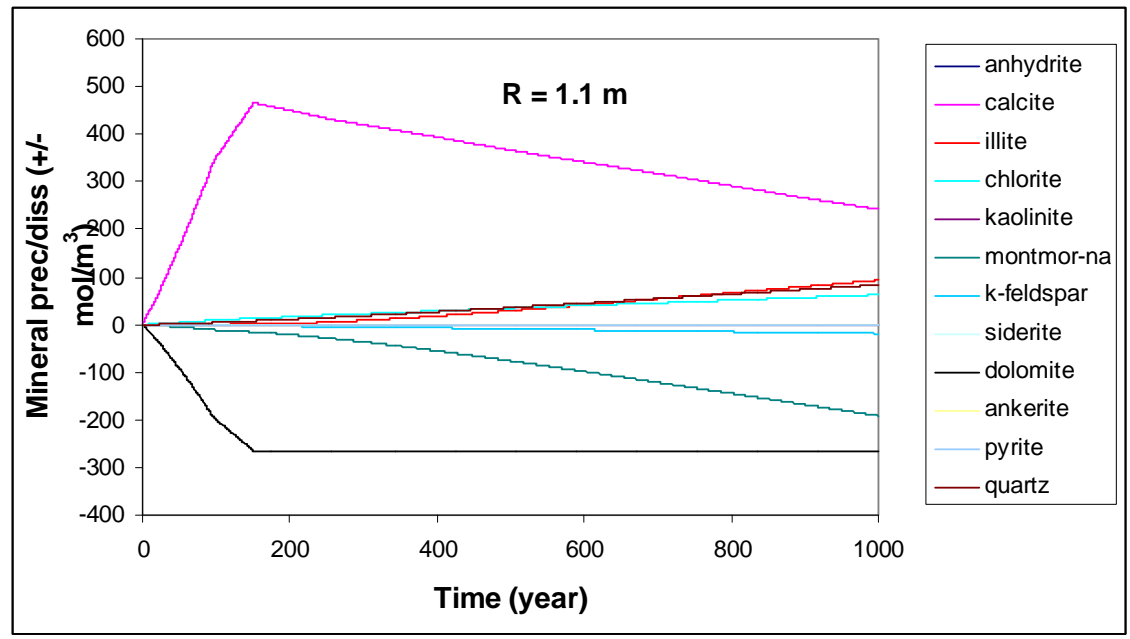

Figure 4-5. Time evolution of minerals dissolution/precipitation at the point inside the bentonite with a radial distance of $1.1 \mathrm{~m}$ (near the bentonite-clay formation interface). 


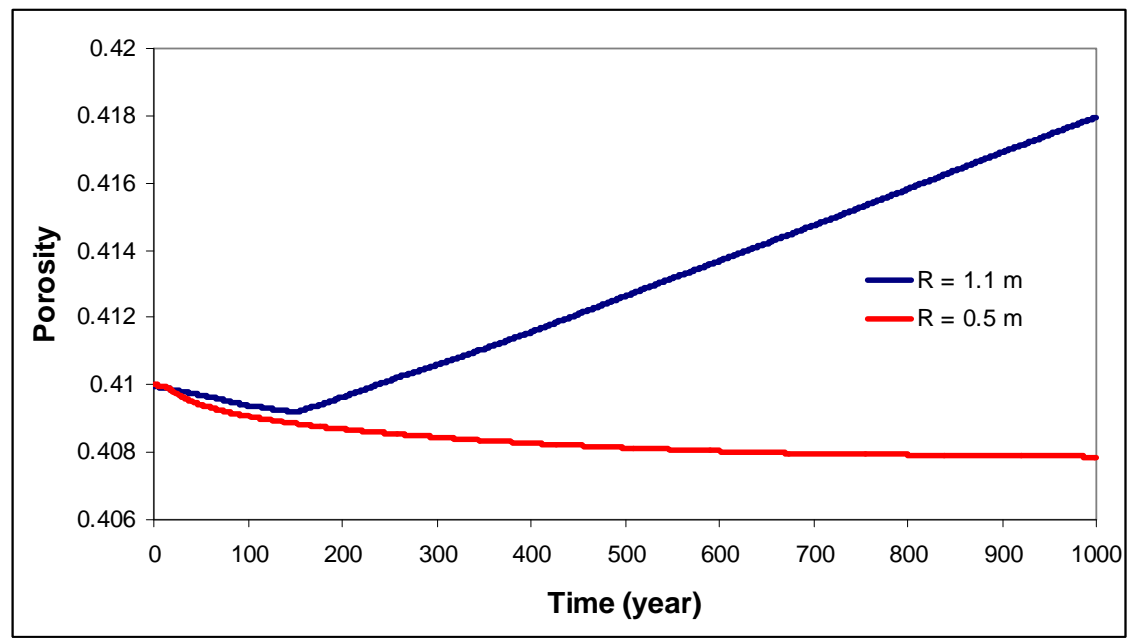

Figure 4-6. Time evolution of the porosity two given locations inside the bentonite.

Figure 4-7 shows time evolution of minerals dissolution/precipitation at the point in the clay formation with a radial distance of $1.2 \mathrm{~m}$ (near the bentonite-clay formation interface). Significant mineral alteration occurs due to the mass transfer between bentonite and clay formation and change of temperature. Minerals alteration at this point is characterized by the dissolution of calcite, siderite and illite and precipitation of ankerite, smectite and quartz. Note that calcite dissolve rapidly in the first 100 years and then precipitate slowly. Correspondingly, ankerite precipitate significantly in the first 100 years and dissolve slowly afterwards. Porosity change is a result of change of all minerals. As shown in Figure 4.9, the porosity in the clay formation near the interface increase slightly and then decrease after 800 years, although such change are just minimal. Figure 4-8 shows the time evolution of minerals in the clay formation far from the interface. Mineral dissolution/precipitation are insignificant which mainly induced by the change of temperature and slight initial disequilibrium. Model results show the dissolution of ankerite, smecitite and illite and the precipitation of anhydrite, quartz and kaolinite, which results in essentially no change of porosity (see Figure 4-9).

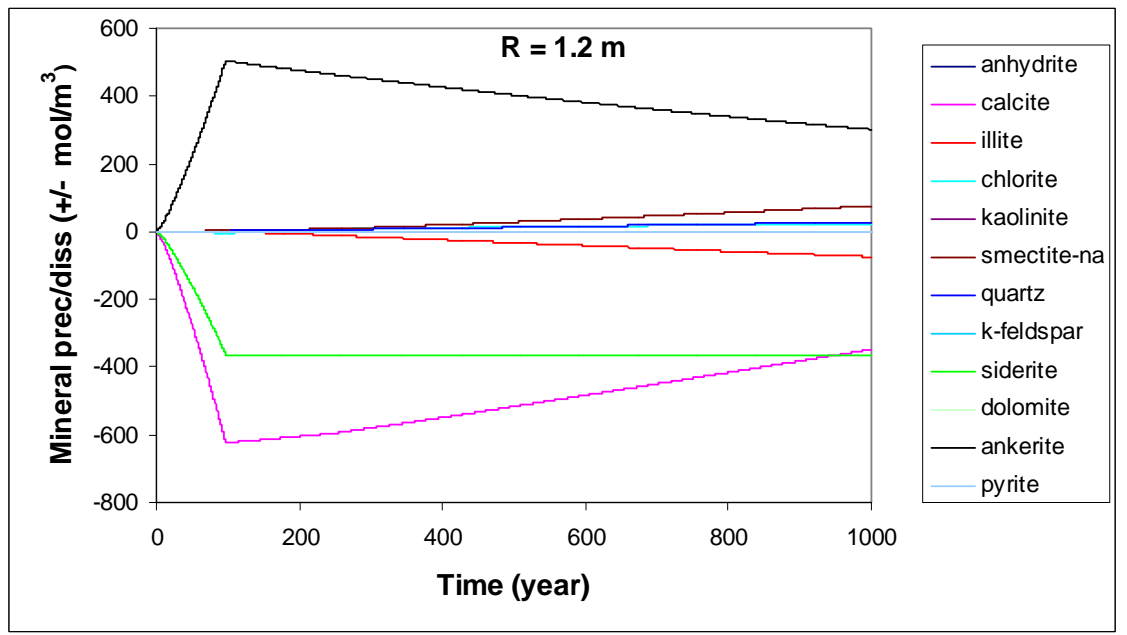

Figure 4-7. Time evolution of minerals dissolution/precipitation at the point in the clay formation with a radial distance of $1.2 \mathrm{~m}$ (near the bentonite-clay formation interface). 


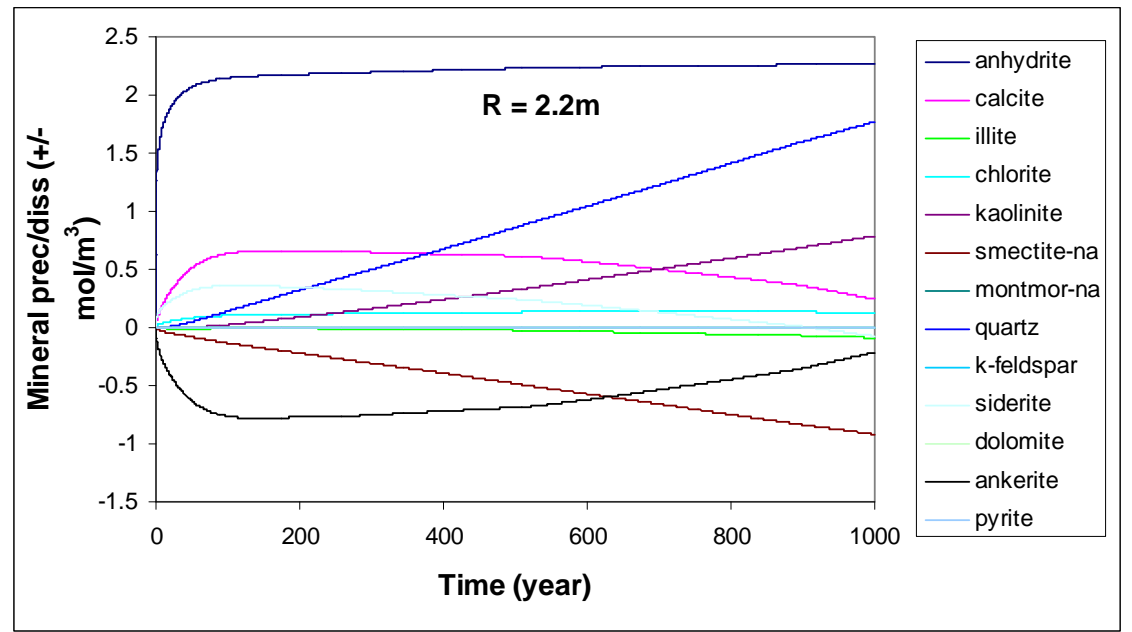

Figure 4-8. Time evolution of minerals dissolution/precipitation at the point in the clay formation with a radial distance of $2.2 \mathrm{~m}$.

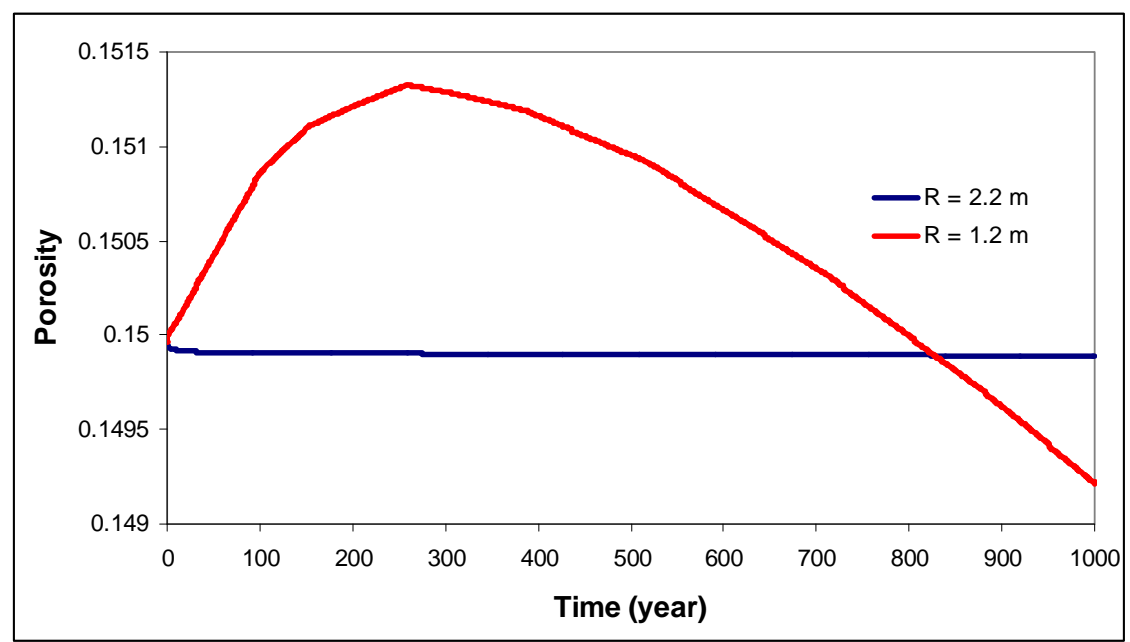

Figure 4-9. Time evolution of the porosity at two given locations in the clay formation.

\section{KNOWLEDGE GAPS AND R\&D PLAN}

\subsection{Knowledge Gaps}

While much progress has been made over the last ten years or more, mostly in Europe (e.g., Tsang et al. 2010), several outstanding theoretical and practical issues remain. These issues concern (a) excavation damaged zone phenomena that result from interaction of the host rock with the excavation and engineered barrier system; (b) larger-scale disturbances to the host rock resulting from seismic, igneous and abnormal pressurization phenomena; (c) characterization of large-scale flow and transport behavior in low-permeability clay/shale formations; and (d) impacts of mineralogical and geochemical conditions on sorption. To resolve these issues, the following knowledge gaps should be investigated: 
1. Constitutive relationships for plastic and indurated clays based on laboratory and analytic studies. This should address issues of elastic limits and fracturing criteria, strain softening for describing progressive change in material strength, and strain localization and shear band occurrence. The impact of hydromechanical, chemical, and thermal effects also needs to be considered (Tsang et al., 2010).

2. Long-term (slow) clay property changes, such as creep in plastic clays and subcritical crack growth in indurated clays. The effects of moisture changes and temperature gradients and chemical environments need to be studied and formulated. How to handle anisotropy and bedding planes (or in general, planes of weakness) has to be resolved (Tsang et al., 2010).

3. Thermo-hydro-mechanical processes in clays. These include damage mechanisms, phase changes, and interaction of multiple materials (such as those in the engineered barrier system). This is an area still requiring much work (Tsang et al., 2010).

4. Impact of rock-property heterogeneity as well as in situ stress fields. The permeability of indurated clays can vary over two orders of magnitude, while mechanical properties can vary by a factor of five or more. Spatial variability may have some characteristic length or may have a fractal character. Understanding clay variability could be key to predicting strain localization and fracturing processes. The stress field may also be spatially varying, depending on local structures and temporal changes in clay properties (Tsang et al., 2010).

5. Changes in recharge, overburden, and regional stress. Changes in stress can lead to fault or fracture reactivation that impacts fluid flow and radionuclide transport behavior in the host rock. Faults in argillaceous rock include both tectonic and non-tectonic faults. In particular, layer-bound, non-tectonic polygonal faults are a phenomenon known to occur only in fine-grained sediments such as clay and shale (Cartwright 1997). These faults may only conduct fluid episodically upon reactivation and are difficult to identify in standard seismic surveys. Mechanisms that could lead to reactivation include sedimentation and glaciation (Mazurek et al. 2003, pp. 341; Caillet 1993), changes in tectonic stress (Darby et al. 2001), seismic or igneous activity, the accumulation of hydrocarbon or nonhydrocarbon gas (e.g, $\mathrm{CO}_{2}$, and $\mathrm{He}$, Wiprut et al. 2000), and osmosis driven by changes in recharge and natural contrasts in solute concentrations of pore waters (Neuzil 2000). Fracture and fault behavior for a clay or shale host rock is sensitive to the diagenetic history. Diagenetic history and the future path of diagenesis have important effects on mineralogical, geomechanical, and hydrological characteristics of the host rock. Some success in understanding diagenetic history has been achieved in European nuclear waste disposal research programs using basin modeling.

6. Intrusion and collapse structures. Other phenomena that can disturb the hydrologic properties of the host rock include intrusions from igneous and hydrothermal activity, clastic intrusions from sandstone or mud, and salt intrusions (Cartwright et al., 2007). Sandstone and mud intrusions occur when overpressurization conditions force sandstone or mud (e.g., mud volcanoes) up through the host rock. Magmatic activity could cause substantial changes to the host rock by the direct intrusion of magma bodies or through mechanical stress induced by the heat and associated vaporization of water. Collapse structures caused by dissolution of evaporites and collapse of source chambers for intrusion material can also lead to host-rock disturbances. 
7. Characterization of host rock properties. Because of the low degree of fracturing and low bulk permeability measured from boreholes or underground excavations (such as underground research laboratories), large-scale permeability values are difficult to ascertain. Infrequent and relatively isolated (preferential) pathways may be difficult to identify based on standard measurement methods.

8. Mineralogical and geochemical conditions and their impact on sorption. There is typically significant uncertainty in the values of the sorption distribution coefficient because these depend on a variety of processes and conditions that take place on complex, heterogeneous, mineral surfaces. There are two specific processes that typically fall under the general label of sorption: ion exchange and surface complexation. Process models are needed for sorption because the number of sorption experiments that are needed to adequately cover the range of current and future geochemical conditions is impractically large. A variety of phenomena could lead to spatial and temporal variations in geochemical conditions that impact sorption including waste heat, hyperalkaline solutions from groundwater interaction with EBS cement, competition between radionuclides and other dissolved species for sorption sites, changes in natural recharge composition, and igneous and geothermal processes. Because sorption is affected by such phenomena, modeling methods to assess mineralogical and geochemical conditions are also needed.

\subsection{Research \& Development Plans for Clay/Shale Host Rock}

The R\&D plans to address the technical issues identified above are divided into near-term (FY11) plans and longer-term plans.

\subsubsection{Near-term R\&D Plans}

Near-term R\&D plans refer to activities that could start in the next fiscal year.

\subsubsection{Experimental Investigation of Fracture Growth, Sealing, and Healing Associated with EDZ Evolution in Clay Formations}

Long-term performance of a nuclear waste repository depends on the extent and nature of the Excavation Damaged Zone (EDZ) around underground structures and the time-dependent processes during the transient stage until an equilibrium is reached (e.g., heat production from the decay of the waste, re-saturation processes) (Blümling et al., 2007). The objective of the proposed work is to improve understanding of fundamental processes governing the long-term evolution of the EDZ in a geological repository hosted in clay formations. Specifically, the proposed work will focus on the issue of fracture growth, sealing and healing within the EDZ.

Investigations at European underground rock laboratories have shown that an EDZ occurs in both soft plastic clays as well as indurated and more brittle clays (Blümling et al., 2007). Upon excavation, the rock adjacent to a tunnel wall is subject to mechanical extension, compression, and shear, causing fracturing, shear and dilation. The resulting fracturing pattern can be complex and strongly impacted by anisotropy in the host rock, as well as by relative humidity changes during ventilation. After emplacement of waste packages and backfill, re-saturation of the rock 
and swelling of the clay take place as well as increases in temperature and the recovery of ground water pressure. Time-dependent deformation (convergence) of the tunnel and the swelling of clay seal (hydraulically) and heal (mechanically) fractures in the EDZ, which then diminishes in spatial extent and magnitude.

In addition to hydromechanical effects, Van Geet et al. (2008) observed that clay swelling and resulting sealing of fractures are augmented by chemical reactions affected by the chemical composition of the water. For more comprehensive understanding of fracture sealing/healing behavior, clay and clay-rich rocks with different clay content, consolidation, and clay types (e.g., smectite, kaolinite, illite) need to be examined. Also, for a fracture within relatively lithified rock with small swelling clay content, mineral precipitation and dissolution within the fractures and microcracks becomes more important, especially under elevated temperature and for long duration.

The proposed task will examine the coupled behavior of fracture healing and sealing within EDZ using millimeter-scale cores to tens-of-centimeter-long cores. Near-term tasks are to initiate hollow cylinder compression tests, shaped-core uniaxial compression tests, and true-triaxial compression tests. Fractures and microcracks will be introduced in these cores, and subsequent sealing and healing will be monitored under a range of temperature, stress, and pore and fracture fluid chemistry. Miniature-core experiments, microtomography imaging will be conducted at the x-ray synchrotron beamline 8.3.2, at LBNL Advanced Light Source, using a specifically designed micro triaxial cell. For the experiments using larger cores, a medical x-ray CT scanner will be used. The monitoring will include stress-displacement measurements, permeability measurements, acoustic (seismic) measurements, and fluid sampling (for geochemical analysis). The obtained experimental data will be used to provide quantitative information for calibrating and verifying numerical models.

\subsubsection{Constitutive Relationships for Coupled Processes in Clay Repositories}

To understand and model the coupled processes and their impact on repository performance requires knowledge of constitutive relationships for the host rock, especially relationships between hydraulic and mechanical properties, because these relationships control the degree of coupling among the relevant processes. Although considerable efforts have been made in developing constitutive relationships, the following important issues (associated with clay rock) have not been fully addressed in previous studies:

Water-content dependent swelling. Multiphase flow conditions develop in the excavation damaged zone (EDZ). Clay rock swells (or shrinks) with increasing (or decreasing) water content, resulting in significant rock property changes (including self-sealing of fractures). Previous studies on constitutive relationships have been focused on single-phase flow conditions and therefore their results are not applicable to swelling conditions.

Fracture properties. Connected fractures exist within the EDZ and may serve as paths for fast flow and radionuclide transport in a clay repository. However, there are only limited studies on constitutive relationships for fractures in clay rock in the literature. 
Correlation between hydraulic and mechanical properties. Assessment of the impact of rock mechanical deformation on flow and transport needs knowledge regarding how the deformation is related to hydraulic property changes. At this stage, acceptable relationships for describing such a correlation are still lacking for fractured clay rock associated with swelling and shrinkage.

Near-term tasks are:

(1) A comprehensive literature survey of laboratory testing data of clay rock deformation under different stress conditions and the associated hydraulic properties. This survey will be analyzed with a focus on improving our understanding of mechanisms of coupled hydro-mechanical processes associated with swelling. The data will also be used for developing and validating constitutive relationship models.

(2) Develop new stress-strain relationships by extending the work of Liu et al. (2009) on elastic strain-stress relations, considering the dependence of mechanical properties on water content, and incorporating the new developments in the area of damage mechanics. Relationships to be developed will be verified by laboratory test data collected under a wide range of conditions.

\subsubsection{Improved Model for Large-Scale Radionuclide Transport in Clay Rocks}

Modeling of diffusive transport in clay rocks (natural system) is complicated by the existence of heterogeneities at different scales and coupling between diffusive and electro-chemical processes (Revil and Leroy, 2004; Appelo et al., 2010; Bourg et al., 2003; Jougnot et al., 2009). At a local scale, different pore spaces co-exist within a representative elementary volume (REV), or a "point" within the context of continuum mechanics. They include pore spaces surrounded by grains other than clay, pore spaces surrounded by clay and other grains, pore spaces surrounded by clay grains only, and interlayer spaces within clay grains. Dominant transport processes of radionuclide can be quite different for different pore spaces. For example, the coupling between diffusive and electro-chemical processes, or interaction between diffusion in bulk fluid and electrical double diffusion layer near the clay surfaces, is negligible for pores surrounded by other grain particles, but critical for small pores surrounded by clay particles and inter-layer spaces. The last two pore-spaces are especially important for compacted clay systems (such as clay buffers in EBS). At large scales, diffusive transport may be subject to a considerable degree of spatial variability as a result of variability of physical and chemical properties of pore spaces. It is also well known that large-scale diffusive process is not isotropic in clay rocks (Motellier, 2007). Diffusion coefficient is much larger along the bedding direction than that in the direction perpendicular to the bedding.

In the literature, two kinds of modeling approaches for diffusive transport in clay materials are available (Revil and Leroy, 2004; Appelo et al., 2010; Bourg et al., 2003; Jougnot et al., 2009). One is based on the explicit consideration of coupling between diffusive and electro-chemical processes. This approach can relatively accurately capture mechanisms of diffusive transport at small scales and is specifically useful for dealing with radionuclide transport in clay buffer systems. This research topic discussed in the proposal concerning diffusive transport in the EBS (Steefel et al. 2010). However, it is relatively computationally intensive for dealing with large- 
scale problems. The second kind of approaches may be referred to phenomenological approach. It is based on Fick's diffusion law and use semi-empirical constants to roughly incorporate the effects of electro-chemical processes, such as using the "accessible porosity" to consider anion exclusion effects and "surface diffusion" to consider effects of charged clay surface on cation diffusion. While this kind of approaches cannot capture the detailed transport mechanisms, it is relatively simple, computationally efficient, and straightforward to implement. Therefore, these approaches are still widely used for modeling diffusion processes in natural clay systems. Keeping in mind that our interest here is to develop an improved model for large-scale diffusive transport in clay rocks, the focus of this proposed work will be on the phenomenological approaches.

Although different degrees of successes have been obtained by using the currently available phenomenological approaches to analyze several site-specific tests (e.g., Appelo et al., 2010; Motellier et al., 2007), some key questions regarding their usefulness are open, considering the semi-empirical feature of the approaches. For example, a systematic evaluation of their effectiveness in capturing effects of pore-scale heterogeneities (the existence of different pore spaces) is not available yet for general natural clay systems. Large-scale heterogeneity (or spatial variability) may or may not be important for diffusive transport in clay rocks. Again, this is not fully investigated. Answerers to these questions are critical for developing a scientifically defensible and practically useful modeling approach.

Near-term tasks are:

(1) A comprehensive literature survey of diffusion test data in natural clay rocks and the associated analysis results will be performed. The survey results will be documented in a project report and/or journal article and employed for evaluating and developing modeling approaches for the diffusive transport processes.

(2) Data sets for typical clay formations will be analyzed with three different modeling approaches. The first one is the traditional approach that is based on Fick's law and uses $\mathrm{K}_{\mathrm{d}}$-type of schemes to consider sorption and the effects of electro-chemical processes. The second approach is based on generalized Fick's law that uses "accessible porosity" to consider anion exclusion effects and "surface diffusion" to consider effects of charged clay surface on cation diffusion. The third one is a new approach (proposed in this study) that borrows the dual-continuum approach (used in describing flow and transport in fractured rock) to deal with the local-scale heterogeneities or the existence of different kinds of pore spaces. This approach, in principle, is consistent with test observations that solute transport in clay rock may be subject to a fast and a slow transport path (Van Loon and Jakob, 2005).

Analytical or numerical approaches will be used for data analyses. These three approaches will be evaluated based on their accuracy in representing the data sets, their usefulness for different clay formations, consistency of parameter values for similar clay formations for a given approach, and numbers of fitting parameters for different approaches. Ultimately, this task will provide guidance on the usefulness and limitations of each approach under different conditions. 


\subsubsection{Impact of Large-Scale Natural Disturbances to Clay/Shale Host Rock}

The condition of a clay/shale host rock repository can be impacted by natural geologic phenomena, both prior to or after waste emplacement. Typically, a clay or shale host rock considered for nuclear waste disposal has bulk permeability in the range of microdarcies to nanodarcies, a key performance characteristic that is significant for impeding radionuclide migration from waste emplacement locations. Therefore, it is important to understand the potential for geologic phenomena to degrade this favorable condition.

Because of their low permeability, argillaceous rocks commonly act as caprocks for trapping buoyant petroleum liquids and gasses. Extensive research into the characteristics of argillaceous rocks as caprocks for petroleum systems (and more recently as caprocks for geologic carbon sequestration) has led to significant findings about how they behave over long time periods. Furthermore, the economic incentive for petroleum exploration has enabled the investigation of argillaceous caprocks over a broader range of geologic environments than is likely to be feasible for nuclear waste disposal.

The overriding observation of significance from petroleum analogues for nuclear waste disposal is that hydrocarbon reservoirs can deplete naturally as a result of caprock failure (Nijhuis 1997). About $50 \%$ of the basins with known petroleum reserves show visible evidence of leakage (Clarke et al. 1991). In other words, although clay/shale caprocks are capable of acting as lowpermeability barriers, these barriers are not absolute and their effectiveness can change over time.

There are several mechanisms leading to caprock failure (Corcoran et al. 2002), including reactivation of exiting faults through tectonic processes or hydraulic overpressure (Cartwright et al. 2007). Furthermore, numerous argillaceous formations have been found to have layer-bound, non-tectonic faults known as polygonal faults (Cartwright 1997). Other mechanisms for caprock failure include intrusions from igneous and hydrothermal activity, clastic intrusions from sandstone or mud, and salt intrusions. Magmatic activity could cause substantial changes to caprocks by the direct intrusion of magma bodies or through mechanical stress induced by the heat and associated vaporization of water. Similarly, the temperature effects of a geothermal system on mechanical stress within the caprock could induce fracturing or fault reactivation. Collapse structures caused by dissolution of evaporites and collapse of source chambers for intrusion material (e.g., mud volcanoes) can also lead to caprock failure. Conditions that may influence such phenomena include the tectonic environment and regional stress field, surficial processes (e.g. sedimentation, erosion, glaciation), stratigraphic composition, sources and compositions of recharge, and the diagenetic history of the host rock.

The near term tasks for this effort are:

(1) The first step is to identify sites with information concerning the current material properties and mineralogy of specific petroleum reservoir caprocks, their diagenetic histories, and information concerning leakage. This task will comprise a literature survey to gather the available information.

(2) The second step is to classify the analogues in terms of leakage or no leakage. The known or suspected mechanism of leakage will be used to further classify the cases with leakage. 
The recent review of seal bypass systems by Cartwright et al. (2007) will serve as a guide for classification.

\subsubsection{Longer-term R\&D Plans}

Longer-term R\&D plans are for activities that require some prerequisite activities to complete or additional plan development.

\subsubsection{Modeling of Fracture Growth, Sealing, and Healing Associated with EDZ Evolution in Clay Formations}

Experimental work will continue longer term to complete tests discussed in Section 5.2.1.1. The laboratory test results will then be used for to check and validate modeling of sealing and healing. This includes simulation of linked reactive transport modeling and geomechanics using the reactive transport simulator TOUGHREACT linked with the geomechanical simulator FLAC3D. We will also test other modeling approaches such as distinct element method (DEM) and boundary element method (BEM) for explicit modeling of fracture propagation, sealing and healing.

A second modeling effort is to investigate behavior at the tunnel scale. The modeling of fracture growth, sealing and healing explicitly will require discrete representation of each individual fracture. However, the evolution of the EDZ is driven by the time dependent processes that require a large scale model of the repository drift within a repository horizon. Therefore, the tunnel scale modeling will be divided into a near-field model domain and a large-scale model domain. The large-scale model domain will be used to derive time-dependent boundary and interior conditions to be imposed on the near-field model domain. The large-scale model simulation will include complete analyses of rock and bentonite buffer, to calculate the evolution of temperature, fluid pressure, bentonite saturation and swelling, and thermal stresses, occurring over a 100,000 year repository lifetime. The near-field model domain allows for a very fine model discretization, enabling detailed studies of fracture growth, sealing and healing in the EDZ.

A similar approach was successfully employed within the international DECOVALEX project for modeling of the EDZ associated with bentonite backfilled repository drifts in crystalline rocks (Hudson et al., 2009; Rutqvist et al., 2009).

The near-field modeling simulations will be conducting using several modeling methods:

(1) Finite element type models with fine element discretization (e.g. ROCMAS, and FLAC3D coupled with TOUGHREACT).

(2) Distinct Element Method (DEM) modeling (e.g. PFC, UDEC).

(3) Boundary Element Modeling (BEM) fracture propagation modeling (FRACON).

All of these modeling methods were recently applied in the international DECOVALEX project for studying the evolution of the EDZ in crystalline rocks (Rutqvist et al., 2009). 


\subsubsection{Constitutive Relationships for Coupled Processes in Clay Repositories}

The work on constitutive relationships initiated with items identified in Section 5.2.1.2 will lead into the following longer-term tasks:

(1) Functional relationships will be investigated between flow properties and mechanical properties for clay rock. A methodology will be developed to estimate the relevant parameter values from common laboratory measurements. Numerical experiments will be performed for investigating multiphase flow behavior under different stress (and damage) conditions. These functional relationships will be carefully evaluated with experimental data obtained from the literature review. Hydraulic and mechanical properties are closely related to geochemical reactions. Pore-scale modeling will be performed to investigate impact of mineral dissolution and precipitation on hydraulic properties.

(2) A dual-continuum (fracture and rock matrix) approach will be developed for modeling coupled processes in the EDZ. Governing equations for multiphase flow and mechanical deformation will be investigated based on the constitutive relationships developed from Tasks 2 and 3. Simulations (using the TOUGH2-FLAC code with the dual-continuum approach to be developed) will be performed for a selected field study site where data are available to demonstrate the usefulness of the new developments from the project.

(3) In the course of these investigations, data gaps and needs will be identified. Laboratory experiments will be performed to address these gaps. They very likely deal with multiphase flow properties under different stress and geochemical conditions subject to swelling and shrinkage. Test results from Section 5.2.1.1 will also be used.

\subsubsection{Improved Model for Large-Scale Radionuclide Transport in Clay Rocks}

The work on large-scale transport modeling methods initiated with items identified in Section 5.2.1.3 will lead into the following longer-term tasks:

(1) It is well known that spatial variability generally has important effects on subsurface flow and transport processes. However, it is not totally clear whether the variability is important for radionuclide (diffusive) transport in clay rock. To evaluate its relative importance, we will computationally generate spatially variable transport-parameter distributions within a two-dimensional domain, and then simulate the diffusive transport (using the numerical method discussed below) by explicitly considering the variability. The simulated breakthrough curves will be compared with those without considering spatial variability. If the difference is significant, an upscaling method will be developed to estimate large-scale transport parameters.

(2) A particle-tracking numerical modeling approach will be developed for radionuclide transport in clay rocks, because it is computationally efficient, easy to implement and has very limited numerical-dispersion for a large-scale problem. In a particle-tracking approach, a continuous concentration field is represented by a great number of solute 
particles whose movements are random and controlled by transport parameters. The particle-tracking approach is also developed in such a way that it can handle the anisotropy of diffusion process that, as discussed above, is common in clay formations with bedding.

(3) Using approaches developed in this investigation, conduct modeling exercises of radionuclide transport in clay formations under different conditions. The modeling results will allow for identification of key parameters, processes, and formation structures for radionuclide transport in a clay repository.

\subsubsection{Impact of Large-Scale Natural Disturbances to Clay/Shale Host Rock}

The evaluation of large-scale host rock disturbance initiated with items identified in Section 5.2.1.4 will lead into the following longer-term tasks:

(1) Select cases that are suitable for further quantitative study as analogues. This includes the development of methods to incorporate various external conditions that affect mechanical conditions in the rock. Factors such as erosion, glaciation, sedimentation, dissolution, tectonics, igneous activity, and geothermal activity need to be considered. This type of analysis is analogous to basin modeling used for petroleum exploration (e.g. Makurat et al. 1992; Kacewicz 2003), however in this case the model will be carried into the future to evaluate the repository performance period. The basin modeling approach has been used to explain burial history of the Opalinus Clay (Mazurek et al. 2003) and hydrologic phenomena in the Paris Basin (Jost et al. 2005) for nuclear waste studies.

The general basin modeling problem for a clay/shale formation includes the effects of burial and uplift, and associated thermal, mechanical, and chemical variations. The impacts of events that could occur entirely within the model domain or events driven by factors external to the model domain need to be added to the basic basin model for diagenesis. Therefore, some method to address coupled processes is required. The study by Rutqvist et al. (2008b) provides a detailed analysis of coupled hydro-geomechanical effects on caprock integrity for $\mathrm{CO}_{2}$ sequestration. Recasting such an analysis for a petroleum reservoir caprock analogue or nuclear waste disposal problem would need to be expanded in terms of the processes under consideration and time frame. The main focus of these exercises is to assess the potential creation or reactivation of faults or fractures and/or creation of intrusion/collapse structures during the performance period, although they may also be useful for evaluating the potential for such host-rock damage to be part of the present-day system.

(2) Use the results from above to identify hydrological, geophysical, and geochemical measurements that can help to define and constrain the effects of bypass systems on clay/shale host rock repository environments.

\subsubsection{Additional Longer-term R\&D}


As outlined in Section 5.1, a number of additional R\&D topics remain to be investigated beyond those with specific plans given in Sections 5.2.1 and 5.2.2. In particular, specific plans need to be developed to address items 7 and 8 in Section 5.1.

\section{SUMMARY AND FEPS CROSSWALK}

\subsection{Summary}

\section{Constitutive Relationships for Elastic Deformation of Indurated Clay Rock}

Constitutive relationships for the hydromechanical behavior of porous and fractured clay rock are developed in this report. It was proposed that for a porous rock, the pore spaces may be subject to large relative strain as compared to the solid grains. Thus, for the pores, relative volumetric strain needs to be defined in terms of the change in rock volume upon a change in stress relative to the total volume at the new stress level. This contrasts with the conventional definition of relative volumetric strain, in which the change in rock volume is taken relative to the total volume at the original stress level. This leads to a reformulation of Hooke's law for the pore spaces within a porous rock in which the differential stress-strain ratio is not a constant but an exponential function of strain. The stress-strain relationships for the solid grains, following the traditional Hooke's law, and the new relationship for pore spaces are combined to give a bulk modulus that is not a constant, but a nonlinear function of stress. Uniaxial test data were analyzed for core samples of Opalinus clay and laboratory measurements of single fractures within macro-cracked Callovo-Oxfordian argillite samples subject to both confinement and water-reduced swelling. This data was used to test the proposed hydromechanical constitutive relationships. Given the nonlinearity and complexities shown in the data, the agreement between the theoretical results and data supports the validity of the proposed constitutive relationships.

\section{THM Processes in Claly/Shale}

There are several software codes available for analyzing THM processes in geologic media. The TOUGH-FLAC and ROCMAS codes were reviewed in detail for this report. The code TOUGHFLAC uses a continuum method to represent fractures and couples thermal-hydrologic modeling using TOUGH with geomechanical modeling using FLAC to address THM processes. The current version of TOUGH-FLAC includes the recently developed BBM, a geomechanical constitutive relationship for thermo-elastoplastic behavior that is observed in bentonite. The code ROCMAS provides a discrete fracture representation for THM process including single-phase unsaturated flow. ROCMAS has several options for geomechanical constitutive relationships but currently does not include the BBM. The ROCMAS code and TOUGH-FLAC are two different types of simulators that complement each other, have been extensively applied, and yet have the flexibilities for modifications and future improvements.

The TOUGH-FLAC software was tested on a full-scale nuclear waste repository problem involving the interaction of multiple components (buffer, canister, rock) over a 100,000 year simulation time. The simulation studies investigated coupled THM processes for a bentonitebackfilled EBS in a low-permeability clay host rock. This study highlight the important interactions between the buffer and the host rock, in particular regarding the potential for desaturation of the rock and thermal pressurization, which can have a significant impact on coupled THM evolution. 


\section{THC Modeling in Clay/Shale}

The TOUGHREACT software code was evaluated as a tool reactive-diffusive transport in a clay/shale host rock. TOUGHREACT is a comprehensive non-isothermal multi-component reactive fluid flow and geochemical transport simulator. Aqueous complexation, acid-base, redox, gas dissolution/exsolution, and cation exchange are considered under the local equilibrium assumption. Mineral dissolution and precipitation can proceed either subject to local equilibrium or kinetic conditions. Linear adsorption and decay can be included. The chemicalhydrological couplings between mineral dissolution/precipitation and fluid flow are included through the treatment of temporal changes in porosity, permeability, and unsaturated hydrologic properties. Transport of aqueous and gaseous species by advection and molecular diffusion are considered in both liquid and gas phases.

An analysis of THC processes was conducted to simulate water-rock interactions around nuclear waste packages emplaced in clay formation with bentonite backfill. Although the analysis is a simplified case, the problem illustrates typical coupled thermal-hydrological-chemical processes that could occur in the EBS and clayey host rock around nuclear waste packages as influenced by the very different near-field mineralogy and water chemistry. The problem includes specific and distinct mineral and pore-water compositions of the bentonite and clay rock, and includes kinetically-controlled mineral precipitation and dissolution reactions. The model computes mineral precipitation and dissolution as well as porosity changes over the first 1000 years following waste emplacement, with a peak temperature of $98^{\circ} \mathrm{C}$. The diffusive mass transfer between bentonite and clay formation and the change of temperature lead to mineral alteration in bentonite and clay formation, especially in the interface area. Minerals alteration in the clay nearfield is characterized by the dissolution of calcite, siderite and illite and precipitation of ankerite, smectite and quartz, while porosity changes are minor.

\subsection{Crosswalk between this Report and FEPs}

The following table identifies work done in this report with the used fuel disposition (UFD) FEPs (Houseworth 2010) associated with clay/shale host rock. 
Table 6-1. FEPs crosswalk

\begin{tabular}{|c|c|c|c|}
\hline $\begin{array}{l}\text { UFD FEP } \\
\text { number }\end{array}$ & UFD FEP name & $\begin{array}{l}\text { Report } \\
\text { Sections }\end{array}$ & Information Provided \\
\hline 1.1 .02 .02 & $\begin{array}{l}\text { Mechanical Effects from } \\
\text { Preclosure Operations }\end{array}$ & 2,3 , and 5 & $\begin{array}{l}\text { Detailed treatment of THM } \\
\text { constitutive relationships and } \\
\text { near-field modeling; brief } \\
\text { review of issues }\end{array}$ \\
\hline 1.1 .02 .03 & $\begin{array}{l}\text { Thermal-Hydrologic Effects from } \\
\text { Preclosure Operations }\end{array}$ & 3 and 5 & $\begin{array}{l}\text { Detailed treatment of near-field } \\
\text { THM modeling; brief review of } \\
\text { issues }\end{array}$ \\
\hline 2.1 .09 .01 & $\begin{array}{l}\text { Chemistry of Water Flowing into } \\
\text { the Repository }\end{array}$ & 4 and 5 & $\begin{array}{l}\text { Detailed treatment of near-field } \\
\text { THC; brief review of issues }\end{array}$ \\
\hline 2.2 .11 .05 & $\begin{array}{l}\text { Effects of Influx (Seepage) on } \\
\text { Thermal Environment }\end{array}$ & 3 and 4 & $\begin{array}{l}\text { Very low natural influx used in } \\
\text { analyses has negligible effect on } \\
\text { thermal environment. }\end{array}$ \\
\hline 2.2 .01 .01 & Evolution of EDZ & 2,3 , and 5 & $\begin{array}{l}\text { Detailed treatment of THM } \\
\text { constitutive relationships and } \\
\text { near-field modeling; brief } \\
\text { review of issues }\end{array}$ \\
\hline 2.2 .08 .04 & $\begin{array}{l}\text { Effects of Repository Excavation } \\
\text { on Flow through the Host Rock }\end{array}$ & None & $\begin{array}{l}\text { Requires additional } \\
\text { investigation, particularly with } \\
\text { respect to the EDZ. }\end{array}$ \\
\hline 2.2 .08 .05 & $\begin{array}{l}\text { Condensation Forms in Host } \\
\text { Rock }\end{array}$ & 3 and 4 & $\begin{array}{l}\text { Sub-boiling temperatures leads } \\
\text { to relatively minor effects of } \\
\text { condensation }\end{array}$ \\
\hline 2.2 .08 .06 & Flow through the EDZ & 2 & $\begin{array}{l}\text { Detailed treatment of THM } \\
\text { constitutive relationships }\end{array}$ \\
\hline 2.2 .09 .61 & $\begin{array}{l}\text { Radionuclide transport through } \\
\text { EDZ }\end{array}$ & 5 & Brief review of issues \\
\hline 2.2 .05 .01 & Fractures & 2 and 5 & $\begin{array}{l}\text { Detailed treatment of THM } \\
\text { constitutive relationships and } \\
\text { brief review of issues }\end{array}$ \\
\hline 2.2 .05 .02 & Faults & 5 & Brief review of issues \\
\hline 2.2 .05 .03 & $\begin{array}{l}\text { Alteration and Evolution of NBS } \\
\text { Flow Pathways }\end{array}$ & 5 & Brief review of issues \\
\hline 2.2 .07 .01 & Mechanical Effects on Host Rock & 2,3 , and 5 & $\begin{array}{l}\text { Detailed treatment of THM } \\
\text { constitutive relationships and } \\
\text { modeling; brief review of issues }\end{array}$ \\
\hline 2.2 .08 .01 & Flow through the Host Rock & 5 & Brief review of issues \\
\hline 2.2 .08 .03 & Effects of Recharge on NBS Flow & 5 & Brief review of issues \\
\hline 2.2 .09 .03 & $\begin{array}{l}\text { Chemical Interactions and } \\
\text { Evolution of Groundwater in Host } \\
\text { Rock }\end{array}$ & 4 and 5 & $\begin{array}{l}\text { Detailed treatment of near-field } \\
\text { THC; brief review of issues }\end{array}$ \\
\hline 2.2.09.51 & $\begin{array}{l}\text { Advection of Dissolved } \\
\text { Radionuclides in Host Rock }\end{array}$ & 5 & Brief review of issues \\
\hline 2.2 .09 .53 & $\begin{array}{l}\text { Diffusion of Dissolved } \\
\text { Radionuclides in Host Rock }\end{array}$ & 5 & Brief review of issues \\
\hline
\end{tabular}




\section{ACKNOWLEDGMENT}

This report has been authored by Lawrence Berkeley National Laboratory under Contract No. DE-AC02-05CH11231 with the U.S. Department of Energy.

\section{REFERENCES}

Alonso E.E., Alcoverro, J., et al. (26 co-authors) The FEBEX benchmark test. Case definition and comparison of modelling approaches. International Journal of Rock Mechanics \& Mining Sciences 42, 611-638, 2005.

Appelo, C.A.J., L. R. Van Loon and P. Wersin, Multicomponent diffusion of a suit of tracers in a single sample of Opalinus clay, Geomochimica Acta 74 1201-1219, 2010.

Appelo, C.A.J., and Postma, D., Geochemistry, groundwater and pollution, Rotterdam, The Netherlands, Balkema, 536 pp., 1993.

Barnichon J.D., Volckaert G. Observations and Predictions of Hydromechanical Coupling Effects in the Boom Clay, Mol Underground Research Laboratory, Belgium. Hydrogeology Journal 11 (1): 193-202. 2003.

Biot, M.A., General theory of three dimensional consolidation. J. Applied Physics, 12, 155-164., 1941.

Blumling P., Bernier F., Lebon P., Martin C.D. The Excavation Damaged Zone in Clay Formations Time-Dependent Behavior and Influence on Performance Assessment. Physics and Chemistry of the Earth 32: 588-599. 2007.

Bower, K.M. and Zyvoloski, G. A numerical model for thermo-hydro-mechanical coupling in fractured rock. Int. J. Rock Mech. Min. Sci. \& Geomech. Abstr., 34, 1201-1211, 1997.

Börgesson, L., ABAQUS. In Stephansson, O., Jing, L., and Tsang, C.-F. editors, Coupled Thermo-hydro-mechanical Processes of Fractured Media. Developments in Geotechnical Engineering, Elsevier, 79, pp. 565-570, 1996.

Bourg, I.C., A. C. M. Bourg and G. Sposito, Modeling diffusion and adsorption in compacted bentonite: a critical review. Journal of Contaminant Hydrology 61, 293-302, 2003.

Caillet, G. The Caprock of the Snorre Field, Norway: A Possible Leakage by Hydraulic Fracturing, Marine and Petroleum Geology, 1993, Vol 10, February, pp. 42-50, 1993.

Cartwright, J. Polygonal Extensional Fault Systems: A New Class of Structure Formed During the Early Compaction of Shales, from Fluid Flow and Transport in Rocks: Mechanisms and Effects, Bjørn Jamtveit, B. W. D. Yardley, 1997.

Cartwright, J.; Huuse, M.; Aplin, A. Seal Bypass Systems, AAPG Bulletin; August 2007; v. 91; no. 8; p. 1141-1166, 2007. 
Clarke, R.H., and Cleverly, R.W. Petroleum Seepage and Post-Accumulation Migration, in England, W.A., and Fleet, A.J., (eds.), Petroleum migration, London, The Geological Society: p. 265-271, 1991.

Corcoran, D.V.; Dore, A.G. Top Seal Assessment in Exhumed Basin Settings - Some Insights from Atlantic Margin and Borderland Basins, in Hydrocarbon Seal quantification: Papers Presented at the Norwegian Petroleum Society Conference. Norsk Petroleumsforening. Editors: Andreas G. Kostler and Robert Hunsdale, Elsevier 2002.

Corkum A.G., Martin C.D. The mechanical behavior of week mudstone (Opalinus Clay) at low stress. International Journal of Rock Mechanics \& Mining Sciences 44: 196-209. 2007a

Corkum A.G., Martin C.D. Modeling a mine-by test at the Mont Terri rock laboratory, Switzerland. International Journal of Rock Mechanics \& Mining Sciences 44: 846-859. $2007 \mathrm{~b}$

Darby, D.; Funnell, R.H. Overpressure Associated with a Convergent Plate Margin: East Coast Basin, New Zealand, Petroleum Geoscience; September 2001; v. 7; no. 3; p. 291-299. 2001.

Dobson, P.F., T.J. Kneafsey, E.L. Sonnenthal, N.F. Spycher, and J.A. Apps, Experimental and numerical simulation of dissolution and precipitation: Implications for fracture sealing at Yucca Mountain, Nevada. Journal of Contaminant Hydrology. 62-63: 459-476, 2003.

Davy C.A., Skoczylas F., Barnichon J.D., Lebon P. Permeability of Macro-Cracked Argillite under Confinement: Gas and Water Testing. Physics and Chemistry of the Earth 32: 667-680. 2007.

Fernandez A.M., M.J. Turrero, D.M. Sanchez, A. Yllera, A.M. Melon, M. Sanchez, J. Pena, A. Garralon, P. Rivas, P. Bossart P. Hernan, 2006, On site measurements of the redox and carbonate system parameters in the low- permeability Opalinus Clay formation at the Mont Terri Rock Laboratory, Physics and Chemistry of the Earth 32 (2007) 181-195

Fouche O., Wright H., Cleach J.L., Pellenard P. Fabric Control on Strain and Rupture of Heterogeneous Shale Samples by Using a Non-Conventional Mechanical Test. Applied Clay Science 26: 367-387. 2004.

Gonzales, S. and Johnson, K.S. Shale and other argillaceous strata in the United States. Oak Ridge National Laboratory. ORNL/Sub/84-64794/1. 1984.

Gray, I. Reservoir Engineering in Coal Seams: Part 1-The Physical Process of Gas Storage and Movement in Coal Seams. SPE Reserv. Eng., 2(1), 28-34, 1987.

Guvanasen, V. and Chan, T. A new three-dimensional finite-element analysis of hysteresis thermohydromechanical deformation of fractured rock mass with dilatance in fractures. Proceedings of the $2^{\text {nd }}$ Conference on Mechanics of Jointed and Faulted Rocks, Vienna, Austria, April 10-14, 1995, pp. 347-442. 
Houseworth, J.E. The DOE Used Fuel Disposition Campaign Features, Events, and Processes (FEP) Evaluation Report for Bentonite/Clay/Shale Systems, DOE Used Fuel Disposition Campaign, Lawrence Berkeley National Laboratory. 2010.

Hudson J A, Bäckström A, Rutqvist J, Jing L, Backers T, Chijimatsu M, Christiansson R, Feng X-T, Kobayashi A, Koyama T, Lee H-S, Neretnieks I, Pan P-Z, Rinne M, Shen B-T Characterising and Modelling the Excavation Damaged Zone (EDZ) in Crystalline Rock in the Context of Radioactive Waste Disposal. Environ Geol, 57, 1275-1297, 2009.

Israelsson, J.I., Short description of FLAC version 3.2. In Stephansson, O., Jing, L., and Tsang, C.-F. editors. Coupled Thermo-hydro-mechanical Processes of Fractured Media. Developments in Geotechnical Engineering, Elsevier, 79, pp. 513-522, 1996a.

Israelsson, J.I., Short description of UDEC and 3DEC. In Stephansson, O., Jing, L., and Tsang, C.-F. editors. Coupled Thermo-hydro-mechanical Processes of Fractured Media. Developments in Geotechnical Engineering, Elsevier, 79, pp. 523-528, 1996 b.

Itasca Consulting Group, FLAC3D, Fast Lagrangian Analysis of Continua in 3 Dimensions, Version 4.0, Minneapolis, Minnesota, Itasca Consulting Group, 2009.

Jaeger J.C., Cook N.G.W., Zimmerman R.W. Fundamentals of Rock Mechanics (4 ${ }^{\text {th }}$ Edn). Malden: Blackwell Publishing. 2007.

Jobmann M, Wilsnack Th., Voigt H.D. Investigation of Damage-Induced Permeability of Opalinus Clay. International Journal of Rock Mechanics \& Mining Sciences 46: 279-285. 2010.

Jougnot, D., Revil, A., and Leroy, P. Diffusion of Ionic Tracers in the Callovo-Oxfordian ClayRock using the Donnan Equilibrium Model and the Formation Factor. Geochimica et Cosmochimica Acta 73, 2712-2726. 2009.

Jost, A.; Violette, S.; Goncalves, J.; Kageyama, M.; Ramstein, G.; Emmanuel, L.; de Marsily, G. Flow and Transport Modelling in the Paris Basin over Geologic Time, IAH -Spanish chapter International workshop: From data gathering and groundwater modelling to integrated management, Alicante, Spain, 4-8 October, 2005.

Kacewicz, M. 3D Basin Modeling Around the World - Example Problems and Solutions, Geological Society of America Abstracts with Programs, Vol. 35, No. 6, September, 2003, p. $338,2003$.

Kohl, T. and Hopkirk, R.J. The finite element program "FRACTure" for the simulation of Hot Dry Rock reservoir behavior. Geothermics, 24, 345-359, 1995.

Kolditz O., Bauer S., Beinhorn M., de Jonge J., Kalbacher T., McDermott C., Wang W., Xie M., Kaiser R., Kohlmeier M. ROCKFLOW - Theory and Users Manual, Release 3.9, Groundwater Group, Center for Applied Geosciences, University of Tübingen, and Institute of Fluid Mechanics, University of Hannover, 2003. 
Koutsabeloulis, N.C. and Hope, S.A., Coupled stress/fluid/thermal multi-phase reservoir simulation studies incorporating rock mechanics. Proceedings of SPE/ISRM EUROCK-98 symposium, Norway, 1998, pp. 449-454.

Lasaga, A.C., J.M. Soler, J. Ganor, T.E. Burch and K.L. Nagy, 1994. Chemical weathering rate laws and global geochemical cycles. Geochimica et Cosmochimica Acta, 58, 2361-2368.

Lasaga, A. C. Chemical kinetics of water-rock interactions, J. Geophys. Res., v. 89, p. 40094025, 1984.

Lichtner, P. C. Continuum formulation of multicomponent-multiphase reactive transport, in Lichtner, P. C., Steefel, C. I., and Oelkers, E. H. (eds.), Reactive transport in porous media, Reviews in Mineralogy, Mineral Society of America, v. 34, p. 1-79, 1996.

Liu, H.H., J. Rutqvist, and J.C. Berryman, On the relationship between stress and elastic strain for porous and fractured rock, Int J Rock Mech \& Min Sci 46, 289-296, 2009.

Liu H.H. and Rutqvist J. (2010) A new coal-permeability model: Internal swelling stress and fracture matrix interaction. Transport in Porous Media 82(1): 157-171.

Liu Q., Zhang C., Liu X. A practical method for coupled THM simulations of the Yucca Mountain and FEBEX case samples for task D of the DECOVALEX-THMC Project. Proc. GEOPROC2006 International symposium: 2nd International Conference on Coupled Thermo-hydro-mechanical-chemical processes in Geosystems and Engineering, HoHai University, Nanjing, China, May 22-25, 2006, 220-225, HoHai University, 2006.

Makurat, A.; Torudbakken, B.; Monse, K.; Rawlings, C. Cenezoic Uplift and Caprock Seal in the Barents Sea: Fracture Modeling and Seal Risk Evaluation, Paper Number 24740-MS, SPE Annual Technical Conference and Exhibition, October 4-7, 1992, Washington, D.C, 1992.

Mazurek, M.; Pearson, F. J.; Volckaert, G.; and Bock, H. Features, Events and Processes Evaluation Catalogue for Argillaceous Media. ISBN 92-64-02148-5. Nuclear Energy Agency. 2003.

Meier P., Trick T., Blumling P., Volckaert G. Self-Healing of Fractures within the EDZ at the Mont Terri Rock Laboratory: Results after One Year of Experimental Work. In: Proceedings of the International Workshop on Geomechanics, hydromechanical and Thermomechanical Behavior of deep argillaceous Rocks: Theory and Experiments, Paris, October11-12, 2000.

Motellier S., I. Devol-Brown, S. Savoye, D. Thoby, and J.C. Alberto, Evaluation of Tritiated Water Diffusion through the Toarcian Clayey Formation of Tournemire Experimental Site (France). Journal of Contaminant Hydrology 94, 99-108, 2007.

Neuzil, C.E. Osmotic Generation of `Anomalous' Fluid Pressures in Geological Environments. Nature. Vol. 403 pp. 182-184 2000. 
Nguyen, T.S. Description of the computer code FRACON. In Stephansson, O., Jing, L., and Tsang, C.-F. editors. Coupled Thermo-hydro-mechanical Processes of Fractured Media. Developments in Geotechnical Engineering, Elsevier, 79, pp. 539-544, 1996.

Nijhuis, H.J. Prediction of Volumes and Risk in Hydrocarbon Exploration: A Quantification of Geology, Geol Rundsch (1997) 86:322-331, 1997.

Noorishad, J., Tsang, C.-F. and Witherspoon, P.A. Coupled thermal-hydraulic-mechanical phenomena in saturated fractured porous rocks: numerical approach. J. Geophys. Res., 89, 10365-10373, 1984.

Noorishad, J., and Tsang, C.-F. ROCMAS-simulator: A Thermohydromechanical Computer Code. In Stephansson, O., Jing, L., and Tsang, C.-F. editors. Coupled Thermo-hydromechanical Processes of Fractured Media. Developments in Geotechnical Engineering, Elsevier, 79, pp. 551-558, 1996.

Nordstrom, D. K., and Muñoz, J. L. Geochemical Thermodynamics, The Benjamin/Cummings Pub. Co., Menlo Park, California, 477 pp., 1986.

Ochs M., Lothenbach B., Shibata M., and Yui M., Thermodynamic modeling and sensitivity analysis of porewater chemistry in compacted bentonite, Physics and Chemistry of the Earth, Parts A/B/C, Volume 29, Issue 1, (2004), 129-136.

Ohnishi, Y. and Kobayashi, A., THAMES. In Stephansson, O., Jing, L., and Tsang, C.-F. editors. Coupled Thermo-hydro-mechanical Processes of Fractured Media. Developments in Geotechnical Engineering, Elsevier, 79, pp. 545-549, 1996.

Palandri, J., and Kharaka, Y. K. A compilation of rate parameters of water-mineral interaction kinetics for application to geochemical modeling, US Geol. Surv. Open File Report 20041068, 64 pp., 2004.

Patriarche D., Ledoux E., Simon-Coincon R., Michelot J., Cabrera J. Characterization and Modeling of Diffusive Process for Mass Transport through the Tournemire Argillites Aveyron, France. Applied Clay Science 26: 109-122, 2004.

Philip J.R. The Theory of Infiltration: 1. The Infiltration Equation and its Solution. Soil Science, 83: 345-358, 1957.

Philip, J.R. and de Vries, D.A. Moisture movement in porous material under temperature gradients. EOS Trans., AGU, 38, 222-232, 1957.

Pine, R.J. and Cundall, P.A. Application of the fluid rock interaction program (FRIP) to the modeling of hot dry rock geothermal energy systems. In Stephansson, O, editor. Proceedings of the International Symposium on Fundamentals of Rock Joints, Björkliden, Sweden, pp. 293-302, 1985.

Popp T., Salzer K., Minkley W. Influence of Bedding Planes to EDZ-Evolution and the Coupled HM Properties of Opalinus Clay. Physics and Chemistry of the Earth 33: 5374-5387. 2008. 
Pruess, K., Oldenburg, C.M., and Moridis, G.M. TOUGH2 User's Guide Version 2. E. O. Lawrence Berkeley National Laboratory Report LBNL-43134, November 1999.

Pruess, K., TOUGH2: A general numerical simulator for multiphase fluid and heat flow, Lawrence Berkeley Laboratory Report LBL-29400, Berkeley, California, 1991.

Pruess, K. TOUGH user's guide, Nuclear Regulatory Commission, report NUREG/CR-4645 (also Lawrence Berkeley Laboratory Report LBL-20700, Berkeley, California), 1987.

Raffensperger, J. P. Numerical simulation of sedimentary basin-scale hydrochemical processes, In Advances in Porous Media, Corapcioglu, Y. C., (ed.), Amsterdam, The Netherlands, Elsevier Science, 440 pp., 1996.

Revil, A. and P. Leroy, Constitutive equations for ionic transport in porous shales, J. Geophys. Res. 109, p. B03208, 2004.

Rutqvist J., Bäckström A., Chijimatsu M., Feng X-T, Pan P-Z., Hudson J, Jing L., Kobayashi A., Koyama T., Lee H-S, Huang X-H, Rinne M. and Shen B. Multiple-Code Simulation Study of the Long-Term EDZ Evolution of Geological Nuclear Waste Repositories. Environ Geol, 57, 1313-1324, 2009.

Rutqvist J. and Moridis G.J. Numerical Studies on the Geomechanical Stability of HydrateBearing Sediments. Society of Petroleum Engineers SPE Journal 14: 267-282. SPE-126129, 2009.

Rutqvist J, Freifeld B, Min K-B, Elsworth D, Tsang Y. Analysis of thermally induced changes in fractured rock permeability during eight years of heating and cooling at the Yucca Mountain Drift Scale Test. Int J Rock Mech \& Min Sci 45, 1373-1389, 2008a.

Rutqvist, J.; Birkholzer, J.T.; Tsang, C.F. Coupled Reservoir-Geomechanical Analysis of the Potential for Tensile and Shear Failure Associated with $\mathrm{CO}_{2}$ Injection in Multilayered Reservoir-Caprock Systems, International Journal of Rock Mechanics and Mining Sciences, Vol. 45 pp. 132-143, 2008 b.

Rutqvist, J. and Tsang, C.-F. A study of caprock hydromechanical changes associated with CO2-injection into a brine formation. Environmental Geology, 42: 296-305. 2002.

Rutqvist, J. and Tsang, C.-F. A fully coupled three-dimensional THM analysis of the FEBEX in situ test with the ROCMAS code: prediction of THM behavior in a bentonite barrier, In: Stephansson, O., Hudson, J.A., Jing, L., (Eds.) Coupled T-H-M-C Processes in GeoSystems: Fundamentals, Modelling, Experiments and Applications. Elsevier GeoEngineering Book Series, Oxford, p. 143-148, 2004.

Rutqvist J., Y.-S. Wu, C.-F. Tsang, and G. Bodvarsson A Modeling Approach for Analysis of Coupled Multiphase Fluid Flow, Heat Transfer, and Deformation in Fractured Porous Rock Int. J. Rock Mech. \& Min. Sci. 39, 429-442, 2002. 
Rutqvist J., Börgesson L., Chijimatsu M., Nguyen T. S., Jing L., Noorishad J., and Tsang C.-F. Coupled Thermo-hydro-mechanical Analysis of a Heater Test in Fractured Rock and Bentonite at Kamaishi Mine - Comparison of Field Results to Predictions of Four Finite Element Codes. Int. J. Rock Mech. \& Min. Sci. 38, 129-142, 2001.

Settari, A., and F.M. Mourits, A Coupled reservoir and Geomechanical Simulation System, SPE Journal, 27(9), 219-226, SPE paper 50939, 1998.

Shi, J.Q., Durucan, S., Syahrial, E. Reservoir Depletion Induced Changes in Coalbed Permeability and Implications for Enhanced CBM Recovery Using $\mathrm{CO}_{2}$ Injection. Geol. Belg. 7, 123-127, 2004.

Slider, H. C., Practical petroleum reservoir engineering methods, An Energy Conservation Science. Tulsa, Oklahoma, Petroleum Publishing Company, 1976.

Sonnenthal, E. Chapter 5 in: Birkholzer, J. Rutqvist, E. Sonnenthal, and D. Barr, 2008, LongTerm Permeability/Porosity Changes in the EDZ and Near Field due to THM and THC Processes in Volcanic and Crystalline-Bentonite Systems, DECOVALEX-THMC Project Task D Final Report, 2008.

Sonnenthal, E., Ito, A., Spycher, N., Yui, M., Apps, J., Sugita, Y., Conrad, M., Kawakami, S., Approaches to modeling coupled thermal, hydrological, and chemical processes in the Drift Scale Heater Test at Yucca Mountain. International Journal of Rock Mechanics and Mining Sciences 42 (2005), 6987-719.

Steefel, C.; Rutqvist, J.; Tsang, C.F.; Liu, H.H.; Sonnenthal, E.; Birkholzer, J. Reactive Transport and Coupled THM Processes in Engineering Barrier Systems (EBS), DOE Used Fuel Disposition Campaign, Lawrence Berkeley National Laboratory, 2010.

Steefel, C. I., and Lasaga, A. C. A coupled model for transport of multiple chemical species and kinetic precipitation/dissolution reactions with applications to reactive flow in single phase hydrothermal system, Am. J. Sci., v. 294, p. 529-592, 1994.

Steefel, C. I., and MacQuarrie, K. T. B. Approaches to modeling of reactive transport in porous media, In Lichtner, P. C., Steefel, C. I., and Oelkers, E. H. (eds.), Reactive transport in porous media, Reviews in Mineralogy, Mineral Society of America, v. 34, p. 83-129, 1996.

Swenson, D.V., DuTeau, R. and Sprecker, T. A coupled model of fluid flow in jointed rock applied to simulation of a hot dry rock reservoir. Int. J. Rock Mech. Min. Sci. \& Geomech. Abstr., 34, Paper 308, 1997.

Thury M. The characteristics of the Opalinus Clay investigated in the Mont Terri underground rock laboratory in Switzerland, C. R. Physique, 3(2002), 923-933.

Tsang, C.-F.; Bernier, F.; Davies, C. Geohydromechanical Processes in the Excavation Damaged Zone in Crystalline Rock, Rock Salt, and Indurated and Plastic Clays - in the Context of Radioactive Waste Disposal, Int. J. Rock Mech.\& Min. Sci. 38, pp. 109-125, 2005. 
Tsang, C.F.; Birkholzer, J.; Liu, H.H. 2010. “A Review of Key Processes and Outstanding Issues Related to Radioactive Waste Repositories in Clay Formations", DOE Used Fuel Disposition Campaign, Lawrence Berkeley National Laboratory.

Van Geet M., Bastiaens W., and Ortiz L. Self-sealing capacity of argillaceous rocks: Review of laboratory results obtained from the SELFRAC project, 2008.

Van Loon, L.R., and A. Jakob, Evidence for a Second Transport Porosity for the Diffusion of Tritiated water (HTO) in a Sedimentary Rock (Opalinus Clay-OPA): Application of Through- and Out-Diffusion Techniques. Transport in porous media 61, 193-214, 2005.

Verma, A., Pruess, K. Thermohydrologic Conditions and Silica Redistribution Near High-Level Nuclear Wastes Emplaced in Saturated Geological Formations, J. Geophysical Res., 93, B2:1159-1173. 1988.

Walter, A.L., Frind, E.O., Blowes, D.W., Ptacek, C.J., Molson, J.W. Modeling of multicomponent reactive transport in groundwater, 1, Model development and evaluation. Water Resour. Res., 30 (11), 3137-3148, 1994.

Wiprut, D.; Zoback, M.D. Fault Reactivation and Fluid Flow along a Previously Dormant Normal Fault in the Northern North Sea, Geology; July 2000; v. 28; no. 7; p. 595-598, 2000.

Wolery, T. J., EQ3/6: Software package for geochemical modeling of aqueous systems: Package overview and installation guide (version 8.0), Lawrence Livermore National Laboratory Report UCRL-MA-110662 PT I, Livermore, California, 1992.

$\mathrm{Xu}, \mathrm{T}$., and K. Pruess, Coupled modeling of nonisothermal multiphase flow, solute transport andreactive chemistry in porous and fractured media: 1. Model development and validation, Lawrence Berkeley National Laboratory Report LBNL-42050, Berkeley, California, 38 pp., 1998.

$\mathrm{Xu}, \mathrm{T}$., and Pruess, K. Modeling multiphase fluid flow and reactive geochemical transport in variably saturated fractured rocks: 1. Methodology, Am. J. Sci., v. 301, p. 16-33, 2001.

Xu, T., E. Sonnenthal, N. Spycher, and K. Pruess, TOUGHREACT: A simulation program for non-isothermal multiphase reactive geochemical transport in variably saturated geologic media. LBNL-56740. Computer \& Geosciences, 32 (2), 145-165, 2006.

Xu, T., Sonnenthal E., Spycher, N. and K. Pruess, TOUGHREACT User's guide: A simulation program for nonisothermal multiphase reactive geochemical transport in variably saturated geologic media. Lawrence Berkeley National Report LBNL-55460-2008, 2008.

Yeh, G. T., and Tripathi, V. S. A model for simulating transport of reactive multispecies components: model development and demonstration, Water Resour. Res., v. 27, p. 30753094, 1991.

Zhang C.L. and Rothfuchs T. Damage and sealing of clay rocks detected by measurements of gas permeability. Physics and Chemistry of the Earth 33: 5363-5373. 2008. 
